$$
\begin{aligned}
& \text { جامعـة المنصــورة } \\
& \text { كليــة التربية }
\end{aligned}
$$

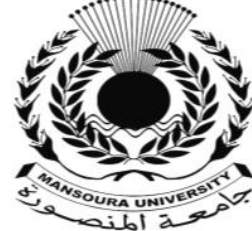

تصميم العاب الواقع المعرز وأثرها في تنسيه المفردات الاغوية للأطفال ذوى النشاط الرزائد

$$
\begin{aligned}
& \text { إعداد } \\
& \text { الباحثة / خلود عبد الفتاح أبو العزم }
\end{aligned}
$$

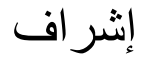

$$
\begin{aligned}
& \text { أ.د/ إسماعيل محمد إسماعيل حسن أ.د/ ريهام محمد أحمد الغول }
\end{aligned}
$$

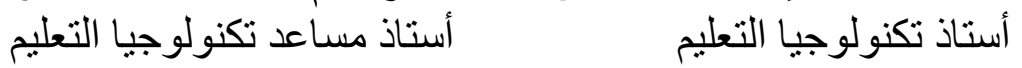

$$
\begin{aligned}
& \text { كلية التربية - جامعة المنصورة }
\end{aligned}
$$

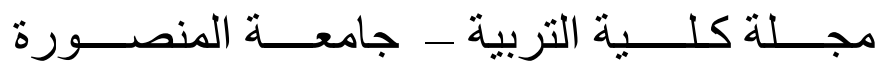

$$
\begin{aligned}
& \text { العدد 11 }
\end{aligned}
$$




\section{تصميم العاب الواقع المعزز وأثرها في تنميه المفردات اللغوية للأطفال ذوى النشاط الزائد}

\section{خلود عبد القتاح أبو العزم}

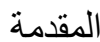

إن مرحلة الطفولة مرحلة إنتقالية حرجة قد يتعرض فيها مسار نمو الطفل إلى مشكلات أو

اضطرابات نفسية أو سلوكية وكمثال لتلك الاضطرابات اضطرابات إفراط الحركة والذى يؤثر على التقدم الأكاديمي للطالب فالنجاح المدرسي يتطلب عادة قدرة الطفل على انتقاء المثيرات ذات العلاقة بالتحصيل الأكاديمي وإهمال المثيرات المتعددة التي يتعرض لها الطفل داخل البيئة الصفية

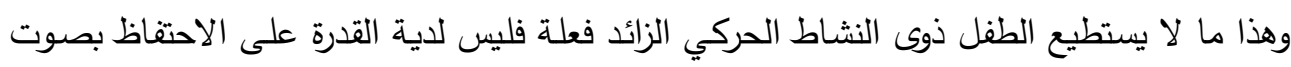

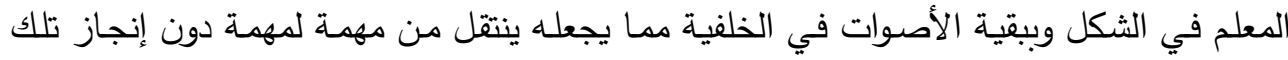

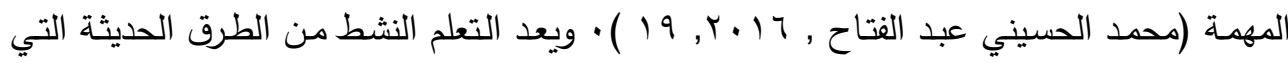
تركز على دور المتعلمين ونقلهم من دور المتلقي إلى دور المشاركة والتفاعل والألعاب التعليمية من أبرز الوسائل التعليمية التي تحقق للمتعلم هذا الدور الإيجابي بما تتضمنه من مواد تعليمية جديدة

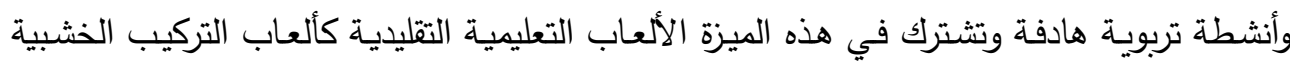

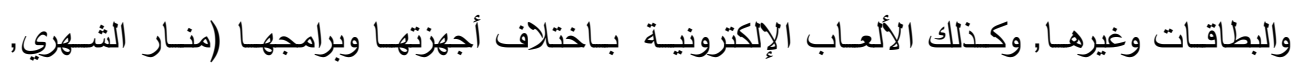

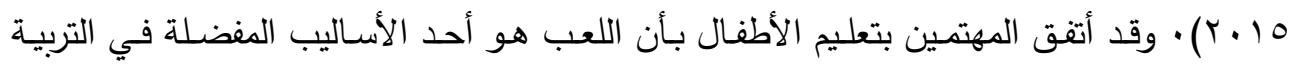
ويعتبراللعب مجالا سمحا للتعبير عن الدوافع والرغبات والاتجاهات والمشاعر والصراعات ولات والات والإحباط وعدم الأمن والقلق والتصريف التتفيسي الإنفعالي ويتيح اللعب فرصة ازاحه المشاعر مثل العات العدوان

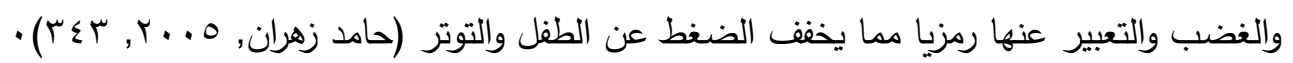

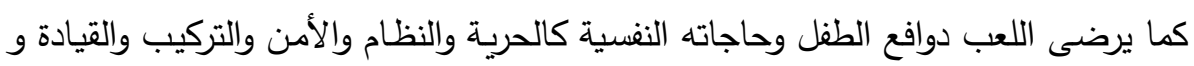

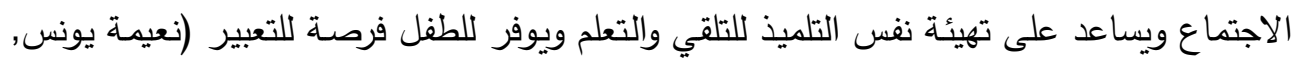

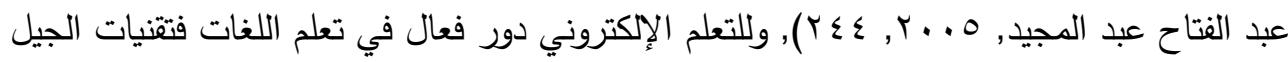
الثاني للويب ومفاهيمـه ساعد في تعلم اللغات الأجنبية ممـا جعل تعلم اللغـة أمرآ ممتعا فالتعليم

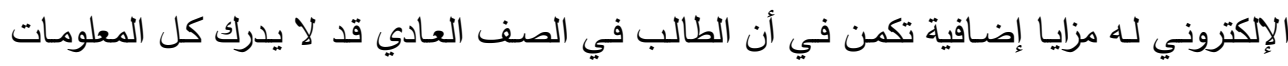

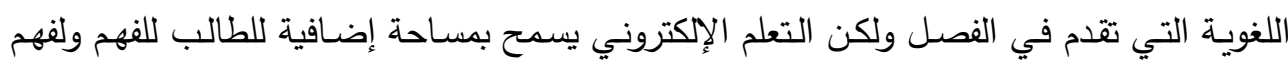
التعابير واستخدامتها ( John Thompson, 2007 ), ومن التطبيقات الحديثة التي يمكن توظيفها في تدريس اللغات هي الواقع المعزز ( Augmented Reality) والتي يمكن توظيفها في العملية 
التعليمسة بهدف تقديم المسـاعدة للمتعلمين ليتمكنوا مـن التعامـل مـع المعلومـات واختبارهـا بشكل

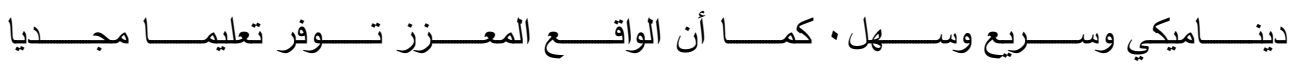

· ( Kipper\&Rapolla, 2013 ) الإحساس بمشكلة البحث:

لاحظت الباحثة وجود قصور في تعلم اللغة الإنجليزيه لاى أطفال الرياض ذوى النشاط الزائد

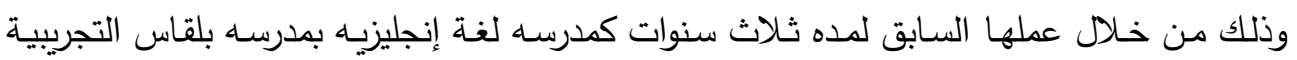

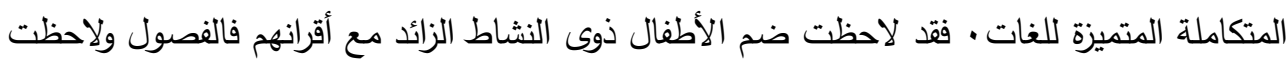
قصور في تعلم مفردات اللغة الإنجليزية وأيضا لاحظت ضعف الإنف مستواهم في كل مهارات اللغوية

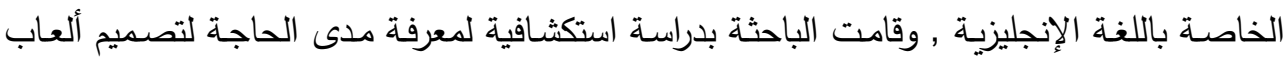

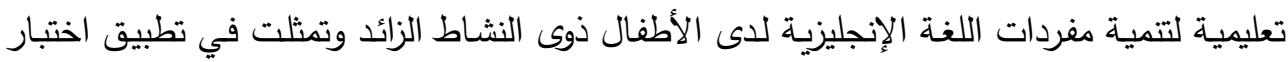

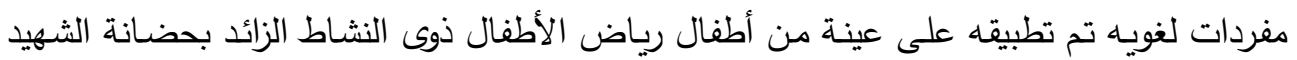

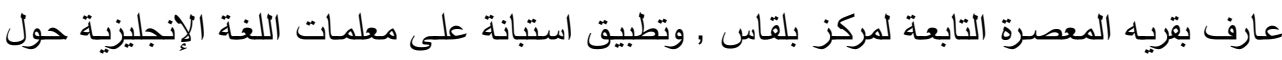

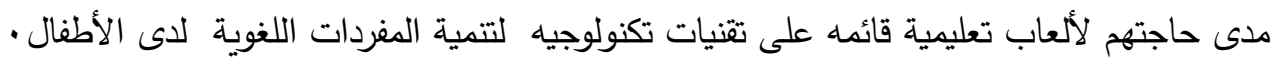

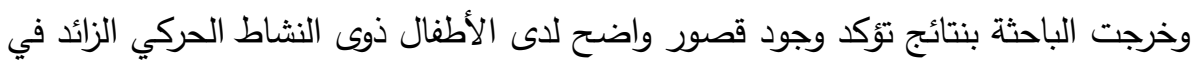

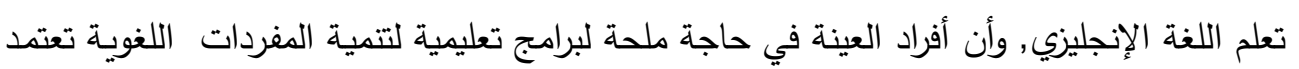

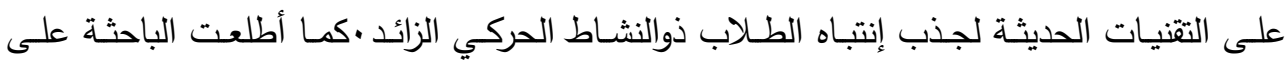
الأدبيات والدراسات وتوصيات المؤتمرات: اولا: الاطلاع على نتائج الدراسات السابقه:

دراسـة Frolva \&Natalia, 2017) والتي أكدت على النى أن التداخل بين تكنولوجيا المعلومات والاتصالات والتقنيات التكنولوجية الحديثة تعمل على تعزيز دافعيه الطلاب وخاصـه في الفي

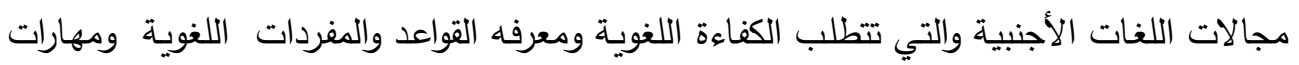
الاستماع والتحدث, بينما أكدت دراسـة نجوين (Nguyen,2008) على أهمية الألعاب التعليمية

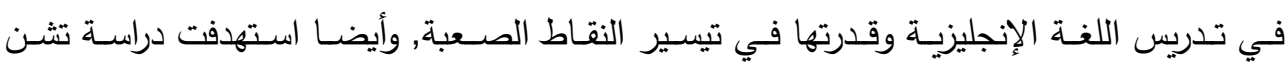
Chen(2013) والتي خرجت بنتائج تؤكد أن أداء الطلاب الذين درسوا باستخدام الواقع المعزز

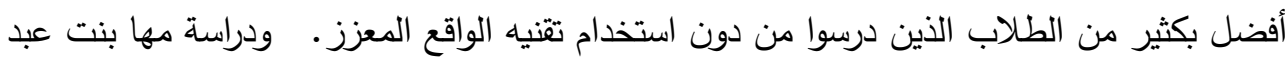

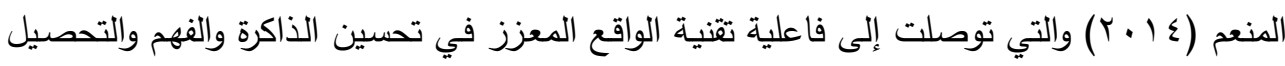

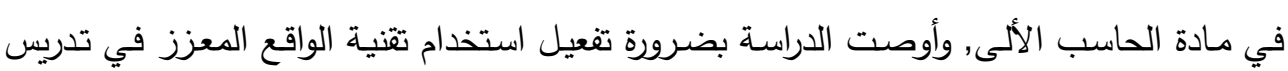


Coshran M, مختف المقررات والبعد عن أسـاليب التدريس التقليدي بينما أكدت دراسـة

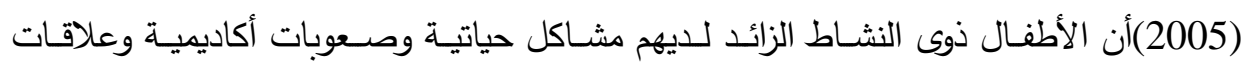

$$
\begin{aligned}
& \text { إجتماعية فالمستوى الأدنى لدى الصبية والبالغين • } \\
& \text { ثانيا : توصيات المؤتمرات والندوات: }
\end{aligned}
$$

أكد المؤتمر العلمي الرابع عشرللجمعية المصرية للتعليم والمقام بجامعة عين شمس بعنوان "

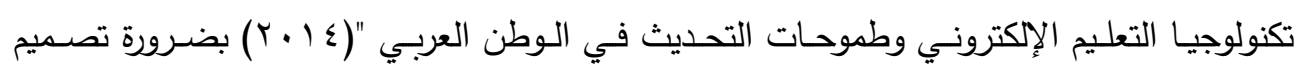
وتطوير تكنولوجيات حديثة مثل الواقع المعزز وتطبيقات الهواتف الذكية.

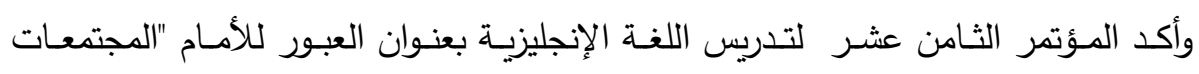
الابداعية, التدريس الملهم وملكية التعلم " (11 + (1) على أن المحاور الرئيسية في المؤتمر الإبتكار

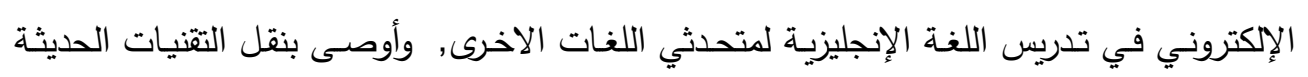

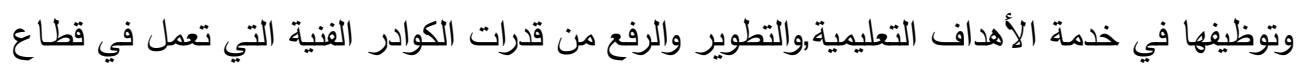
تدريس اللغة الإإنجليزية ومدها بما هوحديث من وسائل وتقنيات في مجال تدريس اللغة الإنجليزية, وتجاوز الصعوبات التي تواجه ذلك على كافة الاصعدة حتى تحصل الفائدة العلمية بنجاح. مشكلة البحث:

تحددت مشكلة البحث الحسالى في ضـرورة استغلال طاقات الأطفال ذوى النشـاط الزائد

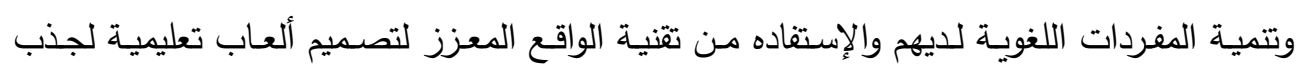
انتباههم و إستغلال طاقتهم وتوجيهها التوجيه الصحيح, وتم معالجة هذه المشكلة من خلال الإجابة

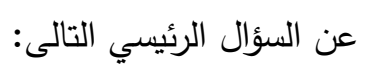

مـا فاعليـة تصـيم الألعـاب التعليميـة باسـتخدام الواقع المعزئ لتنميـة المفردات اللغويـة

للأطفال ذوى النشاط الزائد؟

ويتثرع من هذا السؤال الاسئلة الفرعية التالية:

( ) ما مهارات تعلم مفردات اللغة الإنجليزية لدى الأطفال ذوى النشاط الزائد ؟

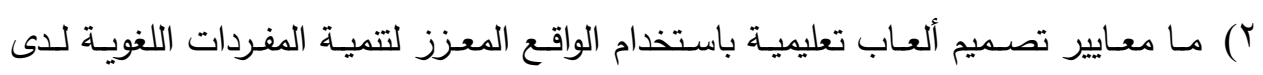

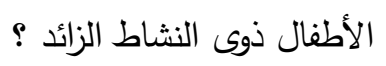

r) ما التصورالمقترح لتصميم الألعاب التعليمية باستخدام الواقع المعزز لتتمية المفردات اللغوية

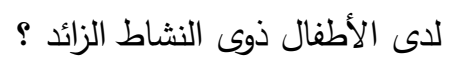


؛) ما فاعلية الألعاب التعليمية باستخدام الواقع المعزز لتتمية المفردات اللغوية لدى الأطفال ذوى

$$
\text { هدف البح البحث: الحالي الزائد؟ البى: }
$$

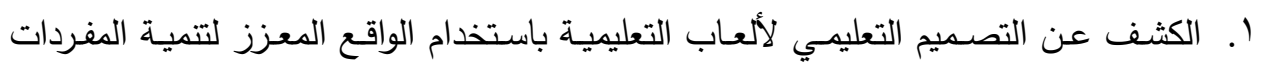

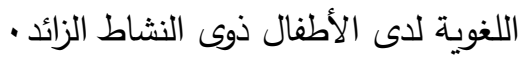

r. الكثف عن أثر استخدام الألعاب التعليمية باستخدام الواقع المعزز لتتميه المفردات اللغويهـ.

$$
\text { أهمية البحث: }
$$

$$
\text { تمثلت أهمية البحث الحالي فيما يلى: }
$$

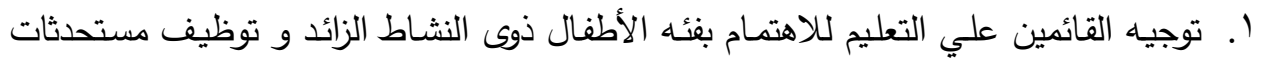

$$
\text { تكنولوجيا التعليم لتوفير عرض شيق وممتع للمواد التعليمية ل }
$$

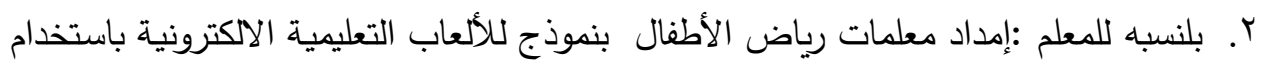

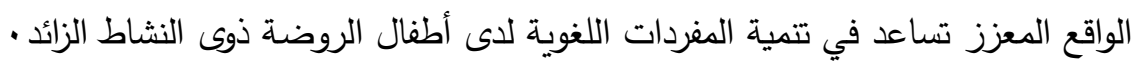

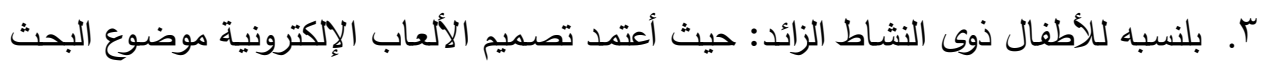
علي تقنيه الواقع المعزز والتي توفر عرض شيق للمواد التعليمية مما يوفر تقدم في تعليم الأطفال ذوى النشاط الزائد .

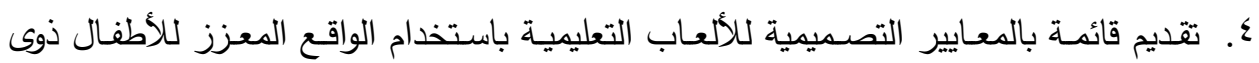

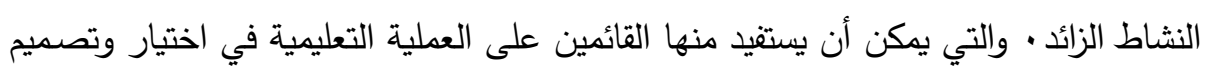
برامج تعليمية لتلك الفئة .

$$
\text { حدود البحث: اقتصر البحث الحالي على ما يلى: }
$$

الحدود البشرية:عينة من أطفال رياض الأطفال ذوى النشاط الزائد بحضانة الثهيد عارف وحضانة

OY يناير - قريه المعصرة- مركز بلقاس - محافظة الدقهلية .

الحدود المكانية: حضانة الشهيد عارف وحضانة هب يناير - مركز بلقاس - محافظه الدقهلية .

الحدود التكنولوجية: تطبيق Unity لتصميم اللعبة التعليمية .

حدود المحتوى: تمثلت في المفردات اللغويـة الخاصـة بالوحدة الثانية من الفصل الدراسي لفي الثاني من ماده اللغة الإنجليزية للمرحلة الثانية من رياض الأطفال .

منهج البحث: استخدمت الباحثة المنهجين التاليين: 
1- المنهج الوصفي التحليلي: لوصف وتحليل أدبيات المجال لإعداد الإطار النظري والبحوث

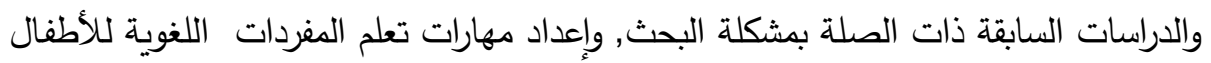

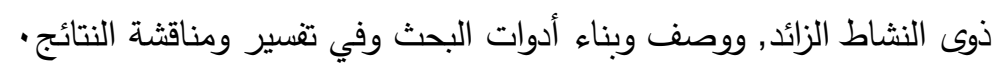
r- المنهج التجريبي: للتحقق من صحة الفروض وتحديد فاعلية تصميم ألعاب تعليمية باستخدام ولئي

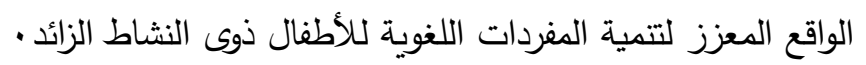

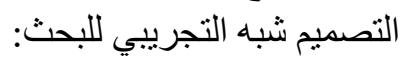
استخذمت الدراسـة التصـميم التجريبـي ذو المجمـوعتين (ضـابطة وتجريبيـة) بقيـاس قبلي

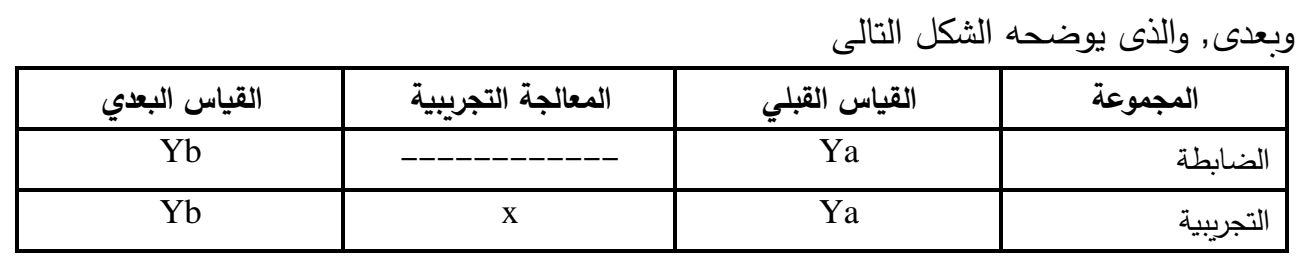
التصميم شبه التجريبي ذو المجموعتين (ضابطة وتجرببية) بقياس قبلى وبعدى فروض البحث: يسعى البحث الحالي للتحقق من صحة الفروض التالية:

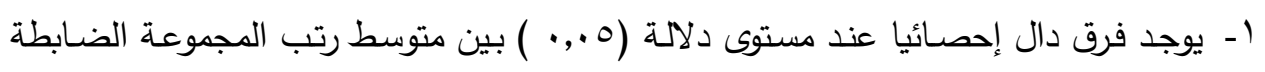

والمجموعة التجريبية في التطبيق البعدي لاختبار التحصيلي لصالح المجموعة التجريبيه.

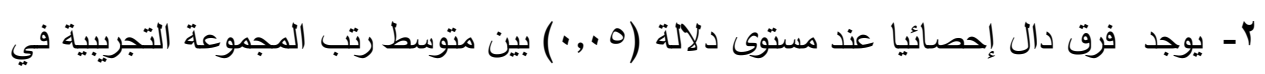
التطبيق القبلي والبعدي للاختبار التحصيلي لصالح التطبيق البعدى . خطوات البحث: للإجابة عن أسئلة البحث اتبعت الباحثة الإجراءات والخطوات الاتية:

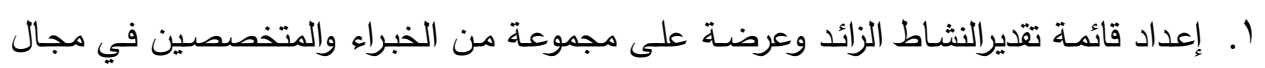

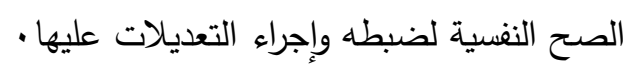

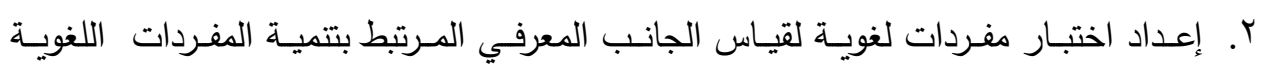

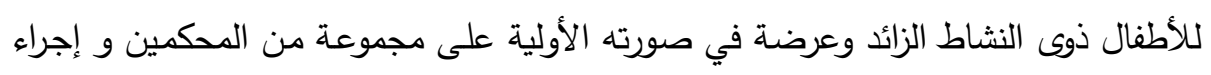
التعديلات ثم إعداده في صورته النهائية .

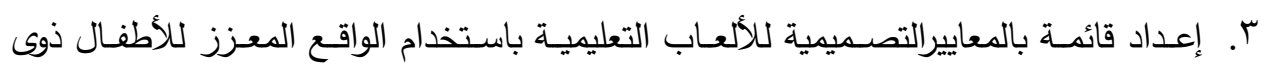
النشاط الزائد, وعرضها على مجموعة من الخبراء والمتخصصين لضبطها و إجراء التعديلات عليها . ع. إعداد نموذج تصميم الألعاب المقترح لتصميم للألعاب التعليمية باستخدام الواقع المعزز · 
๑. تصميم اللعبة التعليمية في ضوء ما تم إعداده من معايير لتصميم الألعاب التعليمية للأطفال

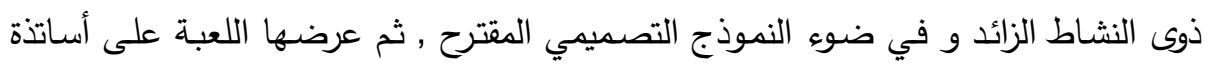

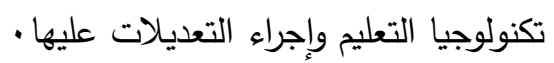
T. ت تم اختيار عينه البحث بصورة قصديه من خلال تطبيق قائمة تقدير النشاط الزائد على أطفال

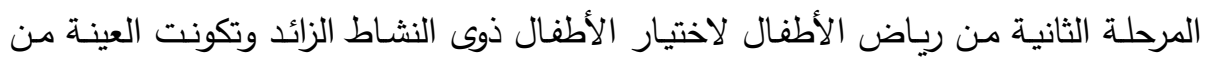

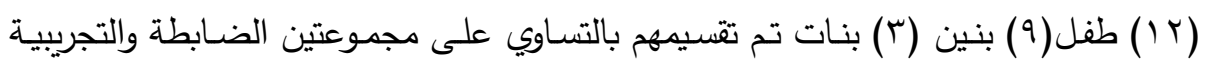
حيث تكونت كل مجموعه من 7 أطفال .

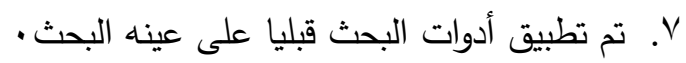

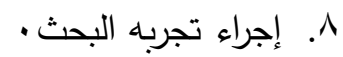
9. تم تطبيق أدوات البحث بعديا على على عينه البحث.

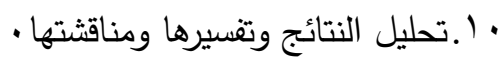

11 .تقديم مجموعه من التوصيات والمقترحات في ضوه النتائج التي تم التوصل إليها . مصطلحات البحث:

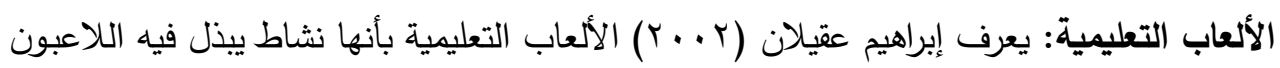
جهودا كبيرة لتحقيق هدفا ما في ضوء قوانين معينة موصوفة .

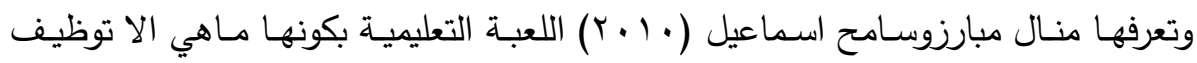

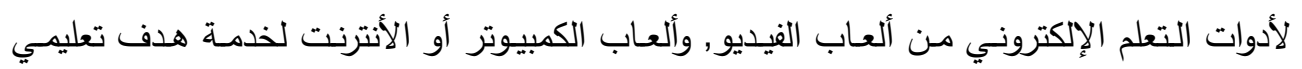

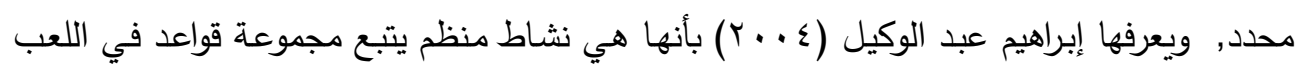
وعادة ما تكون تلك الألعاب على شكل مباريات تعليمية في مقررات مختلفة .

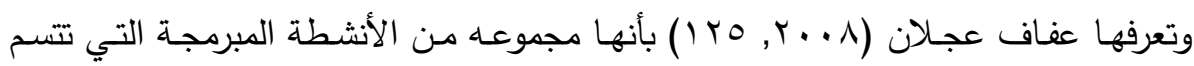
بالتفاعلية والمتعـة والتشويق روإثارة الخيال ممـا تعمل على زيـادة دافعيـه المتعلم, وتعرفها الباحثة

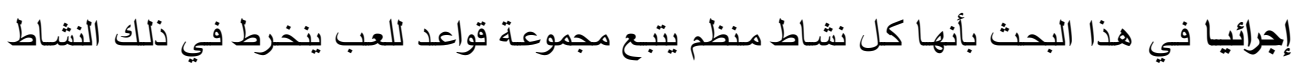

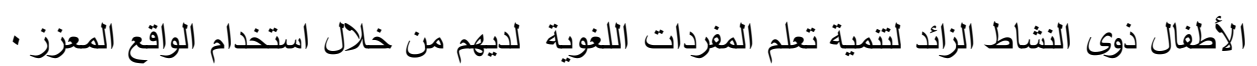

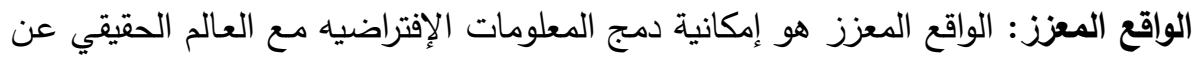
طريق إضافة معلومات مفيدة للإدراك البصرى · ( Looser, J,2007)

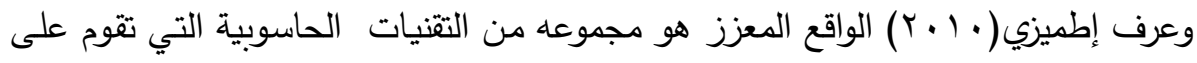

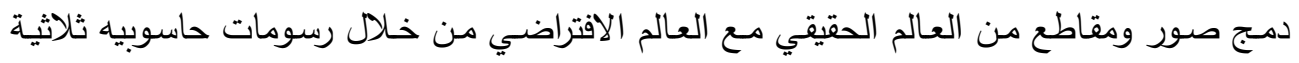


الأبعاد, والواقع المعززهو تقنية تعزز العالم الحقيقة من خلال المحتوى الذى يقوم الحاسب بإنتاجه فتقنية الواقع المعزز تسمح بإضـافة محتوى رقمي بسلاسة لإدراك تصور المستخدم للعالم الحقيقي

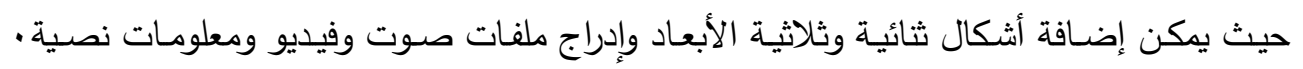

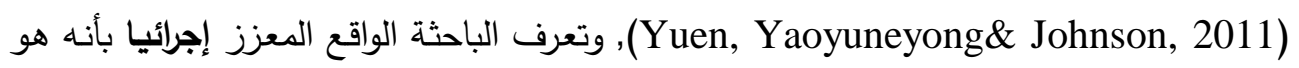
تلك التقنيات التكنولوجية التي يمكن من خلالها توفير بيئة تعليميه منبهه للأطفال ذوى النشاط الزائد

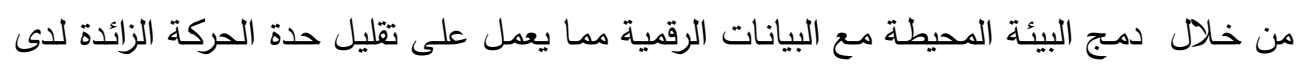

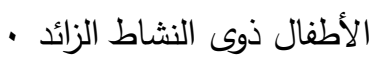

النشاط الزائد: لقد عرفه جمال حامد ( . . . ب) بأنه حركات جسمية فوق الحد المعقول وهو

سلوك إندفاعي مفرط وغير ملائم للموقف وليس لله هدف مباشر ويؤثر على سلوك الطفل, بينما

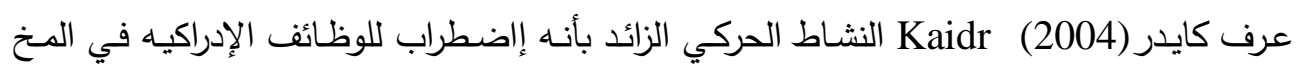

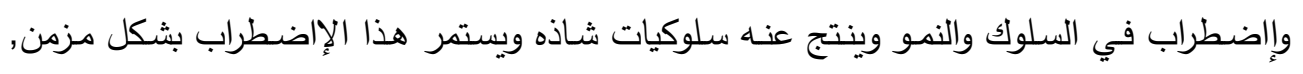

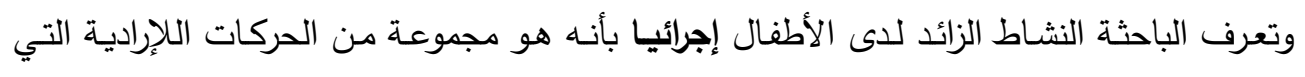
تصدر من الطفل نتيجة لمشكلات في وظائف المخ مما يؤثر على سلوك الطفل ومستواه التعليمي .

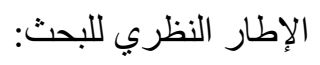
المحور الأول: الألعاب التعليمية الإلكترونية الإنية

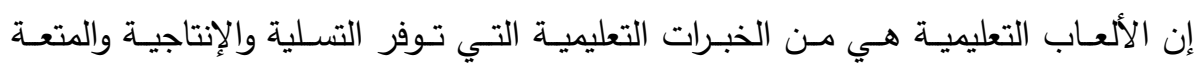

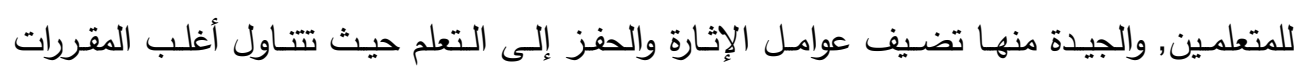

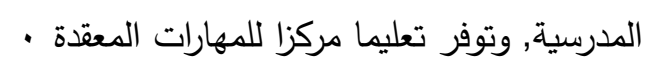

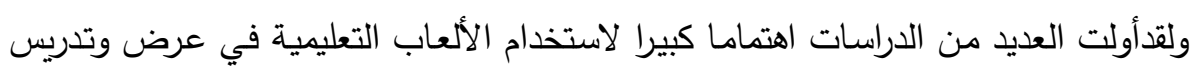

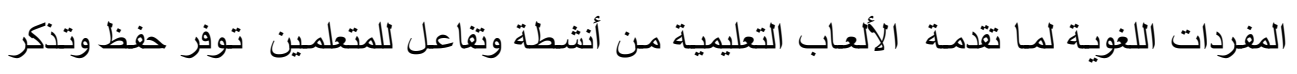
أفضل للمفردة اللغوية, فمن خلال تداخل الصورمع الأصوات في عرض المفردة من خلال اللعبة

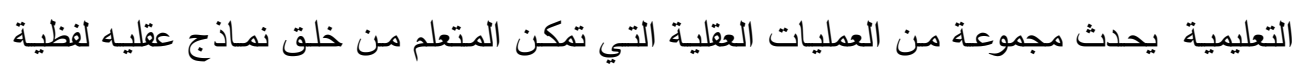

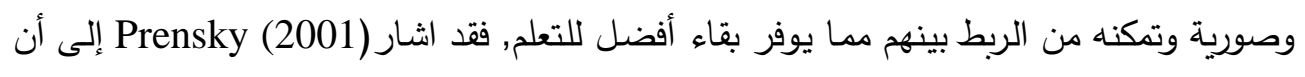

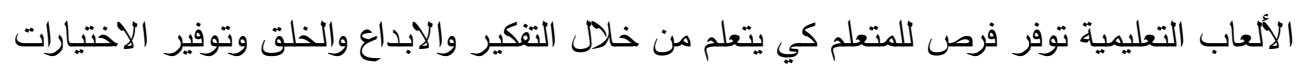

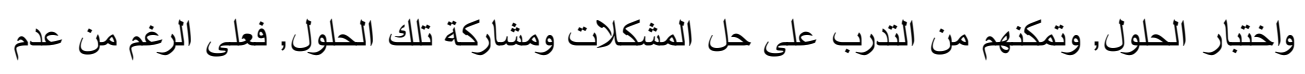

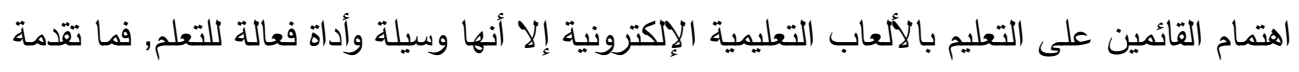

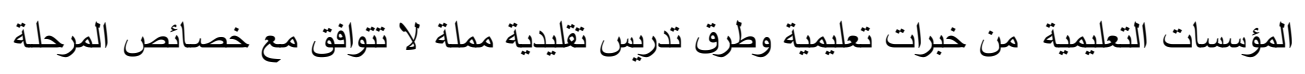


العمريـة للمتعلمين ولا تتوافق مع مـا يواكبه المتعلمين من تطور تكنولوجي هائل, وهناك العديد من

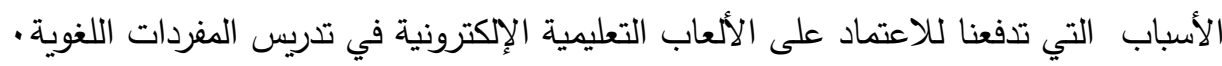

تصنيفات الألعاب التعليمية:

لقد تعددت تصنيفات الألعاب الإكترونية وفيما يلى عرض مبسط لأهم تلابك تلك التصنيفات:

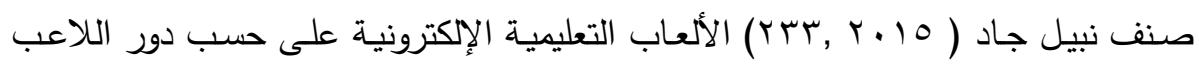

وحسب الهدف وعدد اللاعبين وحسب درجة تعقيدها وفيما يلى عرضا لذلك التصنيف: أولا: التصنيف حسب دور اللاعب:

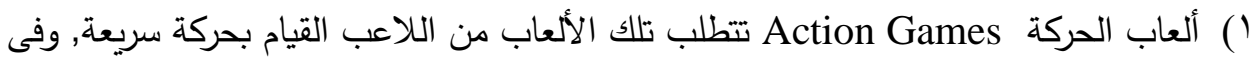

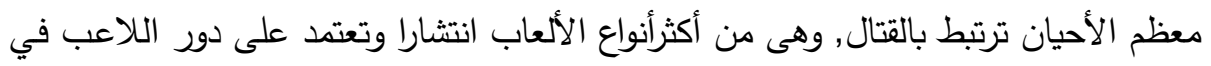
اللعبة من خلال صراع ما أو معركه (Kirriemuier,2004,7) •

r ألعاب المغامرات Adventure Games: وهى تعتمد على عنصر المغامرة والاستكشاف, وغالبا ما تكون خالية من القتال وفيها يقوم اللاعب بحل عدد من الألغاز المنطقية المختلفة من خلال التقاعل بين الثخصيات والبيئة . r) ألعاب الألغاز Puzzle Games: في هذه الألعاب يكون لدى اللاعب فرصة لحل لغز لـن معين لتحقيق مزيد من التقدم في اللعبة وقد تكون محددة بوقت أومفتوحه غير محدده بوقت معين

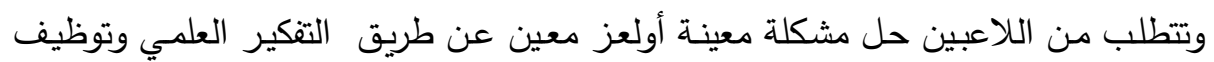

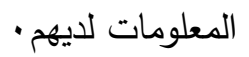

ع) ألعاب تمثيل الأدوار Role Playing Games: تحتوى تلك الألعاب على قصسه غالبا ما تكون أطول من الأنواع الأخرى التي تثتمل على سياق قصصي مثل ألعاب المغامرات · (feil\&Scattergood,2005,186-187)

0) ألعاب المحاكاة Simulation Games: وهى تلك الألعاب التي تحاكى جانب معين من جوانب الحياة وتتطلب تلك النوعية من الألعاب من اللاعب مزج لكل المهارات, والتكتيات,

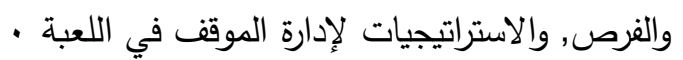

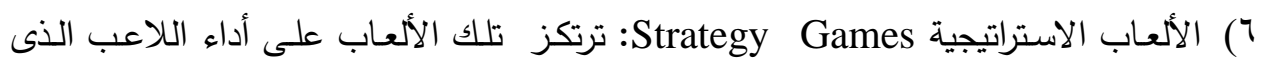
يتطلب منه التفكير الحذر والمخطط للفوز في اللعبة, وتعد تلك الألعاب ألعاب تكتيكيه. ثانيا: التصنيف حسب الهدف من اللعبة: 
( ) الألعاب الإعلانية: تستخدم تلك الألعاب في الإعلان عن المنتجات, وكان أول من أطلق

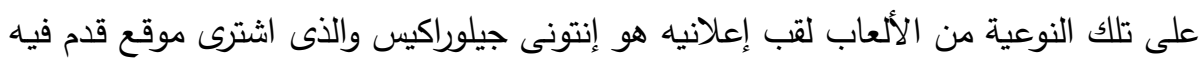
العديد من الألعاب المجانية للإعلان عن منتجات شركاته (Derrberry,2007,3) •

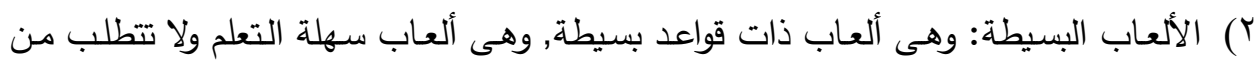

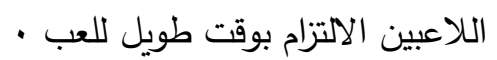
r) الألعاب الجديـة: تصدم تلك الألعاب لتحسين بعض جوانب التعلم, وتستخدم في التدريب العسكري وفى مجال الرعاية الصحية, وفى العملية التعليمية لتحقيق أهداف تربوية وتعليمية

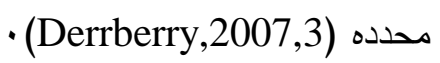
ء) ألعاب التمارين: يهدف هذا النوع من الألعاب على تحسين الحالة الصحية للاعبين من خلال

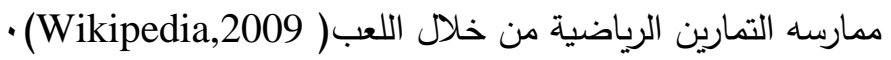
ثالثا: التصنيف حسب عدد اللاعبين:

( ) ألعاب فردية : وهى تلك الألعاب التي يمكن أن يمارسها لاعب واحد مثل ألعاب الألغاز •

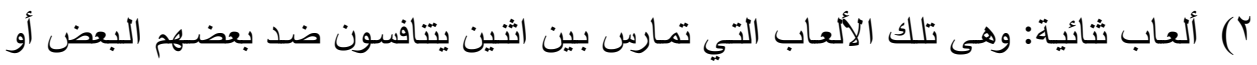
يتعاونون للوصول لهدف محدد.

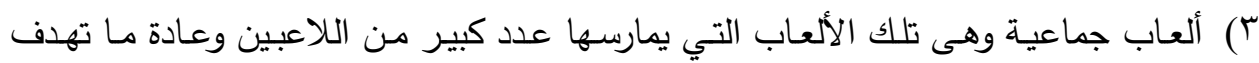
لتتمية التعاون بين اللاعبين - لتان رابعا: التصنيف حسب درجة التعقيد: ( ) ألعاب بسيطة: وهى تلك الألعاب التي عادة ما تستغرق أقل من ساعة في لعبها والتي عادة

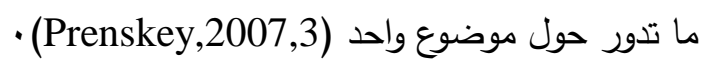

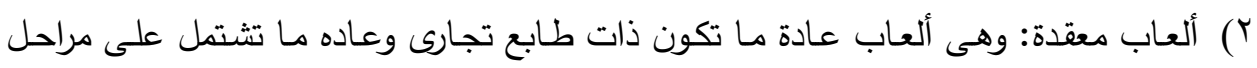

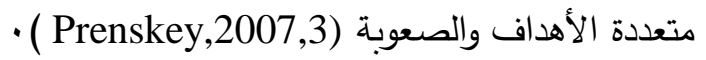
المحور الثاني: الواقع المعزز إن الواقع المعزز يعمل علي دمج للواقع الافتراضي مـع العالم الحقيقي مما يجعل الطالب البعل

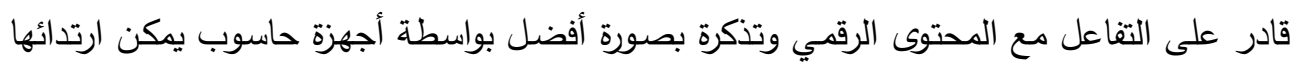
كالنظارات أو شاشات كالهواتف الذكية, ليظهر المحتوى الرقمي كالصور والفيديو والأشكال ثلاثية

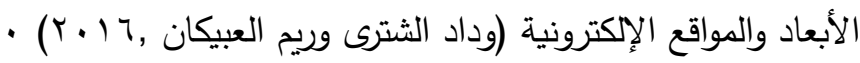

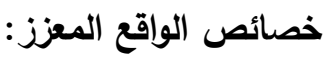


الواقع المعزز يحفز الطلاب على استكثاف المواد والمعلومات من وجهات نظر مختلفة و يساعد على تعلم المواد التي لا يمكن الوصول إليها من خلال التجربة المباشرة كالفلك والجغرافيا,

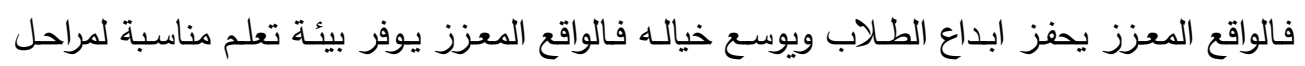

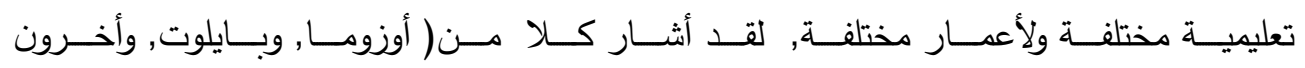

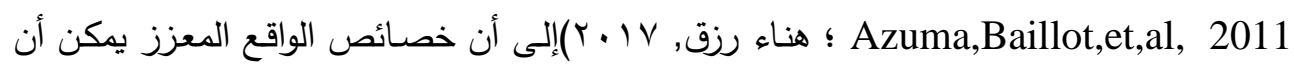

$$
\begin{aligned}
& \text { تتلخص في كونه: } \\
& \text { ( ) ثلاثي الأبعاد - (بونه: }
\end{aligned}
$$

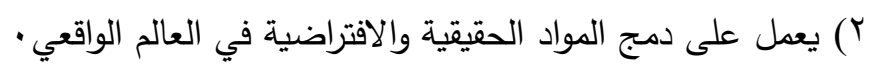

$$
\begin{aligned}
& \text { ץ) يوفر التفاعل الفوري بين المواد الحقيقية والافتراضية . } \\
& \text { ع) يوفر معلومات قوية وواضحة ودقيقة وموجزه • } \\
& \text { 0) يزود الطلاب بالخبرة الحسية الفائقة . }
\end{aligned}
$$

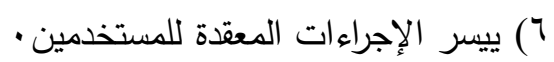

$$
\begin{aligned}
& \text { ( ) فعال من حيث التكلفة وقابل للتوسيع بسهوله . }
\end{aligned}
$$

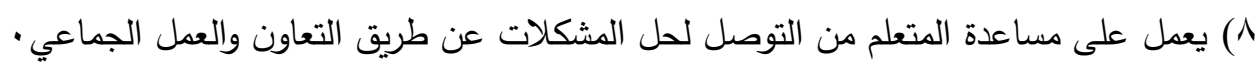

$$
\begin{aligned}
& \text { 9 ) يوفر تعليم مبسط وجذاب يدمج المرح والترفيه لمتعمين • }
\end{aligned}
$$

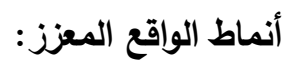

هناك العديد من الأنماط الخاصـة بالواقع المعزز ؛ ومنها مـا أثـار إليه كـلا من (فنسينزى,

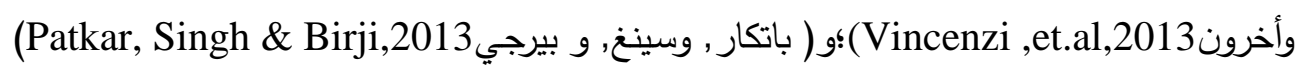
فيما يلى وخرون

ا - الإسقاط: وهو من أكثر الأنواع انتثارا, ويعتمد هذا النوع على إسقاط صور اصطناعيه في

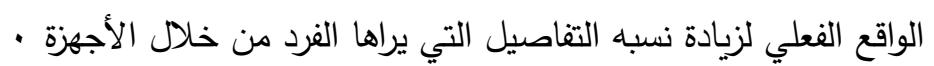

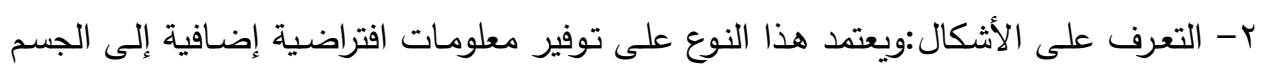

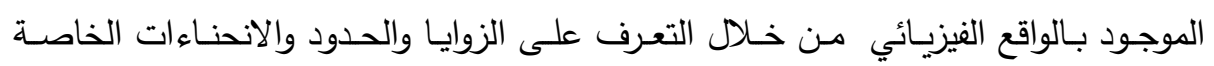

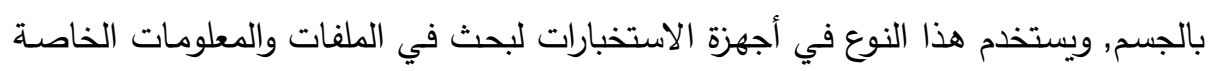

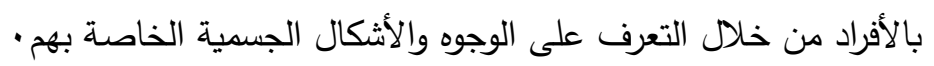


r- الموقع: تستخدم تلك الطريقة لتحديد المواقع من خلال الارتباط ببرمجيات أخرى مثل GPS, Triangulation Technology المطلوب الوصول إليها باستخدام نقاط إلتقاء فرضية وتطبيقها على الواقع, وتتوافر تلك التقنية

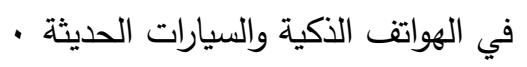

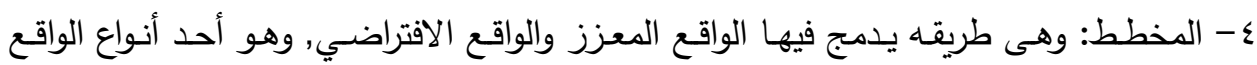

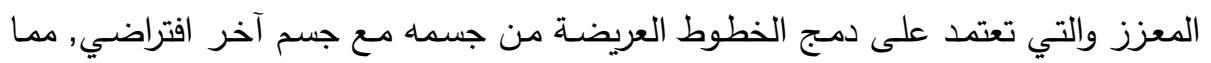

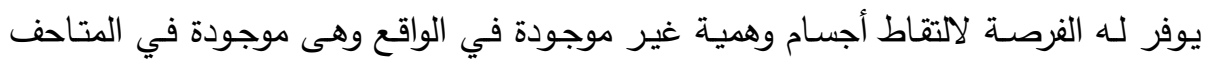
والمراكز العلمية . المحور الثالث: تصميم الألعاب التعليمية الإلكترونية باستخدام الواقع المعزز

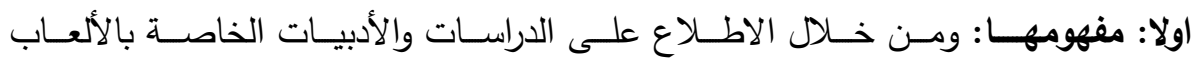

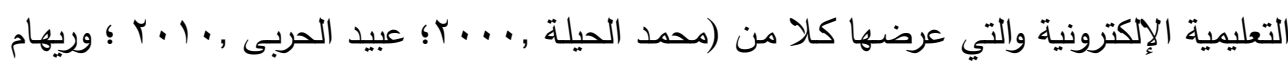

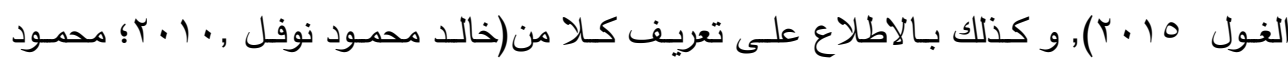

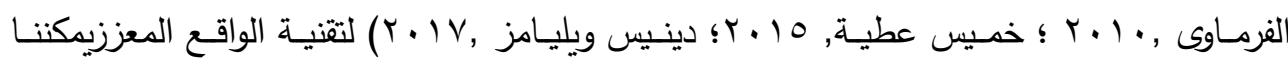
تعريف الألعاب التعليمية الإكترونية باستخدام الواقع المعززبأنها هي كل نشاط تعليمي إلكترونية

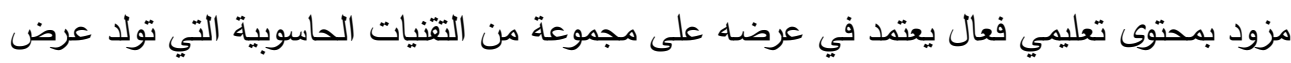

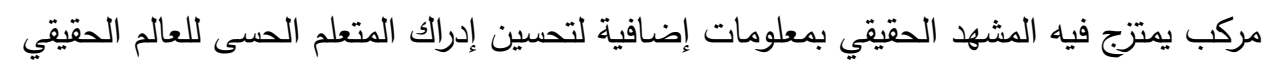

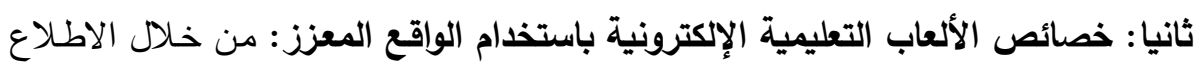

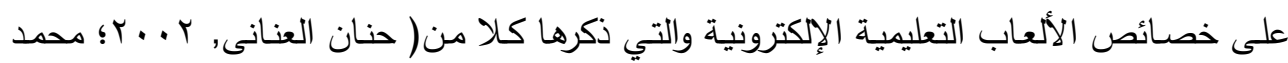

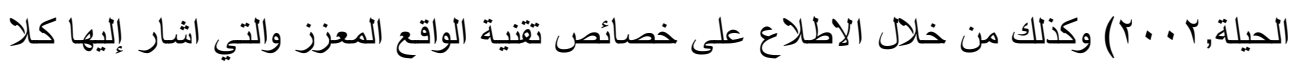

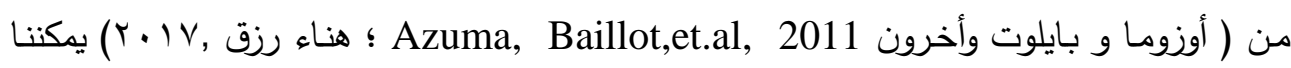
استخلاص خصائص الألعاب التعليمية الإلكترونية باستخدام الواقع المعزز فيما يلى : ( أنشطه حاسوبية تمزج الكائنات الحقيقة والافتراضية في البيئة الحقيقية . (Y r) توفر فرص للتفاعل بين المعلم والمتعلم وتتمى روح التعاون الإيجابي بين المتعلمين •

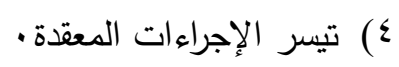$$
\text { 0) تزود الأطفال بخبرات حسيه فائقه . }
$$

ج) تعمل على انغماس المتعلمين في عملية التعلم. 


$$
\begin{aligned}
& \text { توفر مهام تعليمية تفاعلية ثلاثية الأبعاد . V } \\
& \text { ^) توفر معلومات واضحة ودقيقة وقوية - }
\end{aligned}
$$

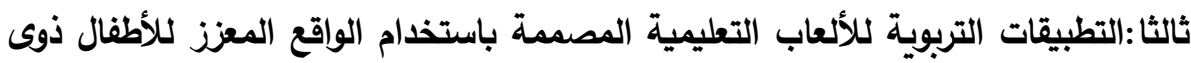

إن الألعاب الإلكترونيـة المعتمـدة على التقنيات التكنولوجيـة الحديثة تسـاعد على جلوس

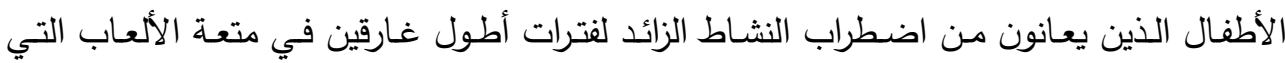

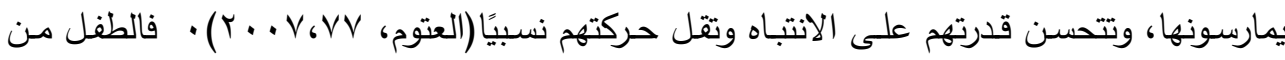

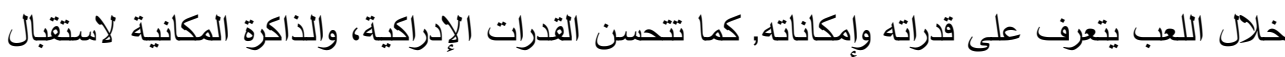
كم هائل من المثيرات التي تؤدي إلى تحسن القدرة على الأداء الأكاديمي وأيضـا يتكون لإدى الطفل الطفل مفهوم واضح عن ذاته, ويتكون لديه أيضا اتجاهات ايجابية نحو ذاته, فأثناء اللعب . وفيما يلى عرض لبعض تلك التطبيقات:

( ) تمثيل المحتوى بطرق جديدة:عادة يتم الحصول على المعرفة العلمية في السياقات التعليمية

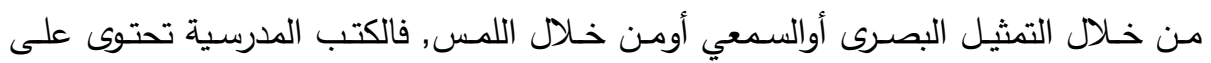
محتوى تعليمي مرئي ثابت كالنصوص والرسوم, ولكن من خلال تقنية الواقع المعزز يمكننا

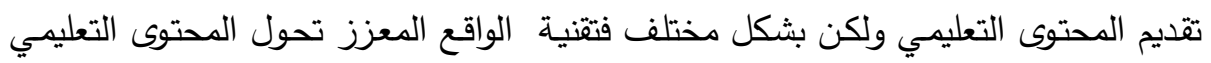
غيرالتفاعلي إلى محتوى تفاعلي, فتتحول الصورالثابتة إلى كائنات ثلاثية الابعاد, وتتحول النصوص المكتوبـة إلى صـوت ويتحول المحتوى التعليمي محتوى تفاعلي نابضـا بالحياة . (Mayer RE, Moreno R, 2003) r) زيـادة فهم المحتوى التعليمي: تقنيـة الواقـع المعزز فعالـة في التـدريس وخاصـة في المواد

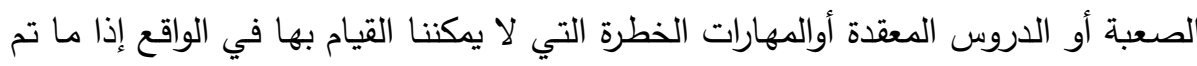

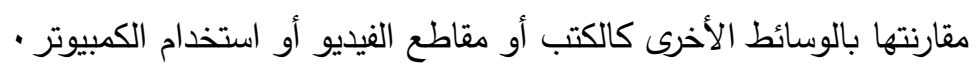

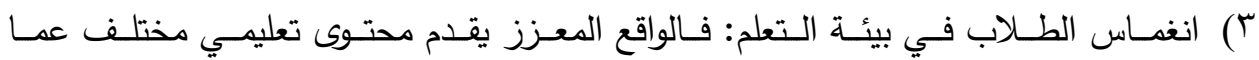
تقدمالوسائط الكمبيوتريـة التقليدية والتى لا توفر الثعور القوى لدى الطلاب بالانغماس في لفي بيئته التعلم, على عكس ما توفره تقنية الواقع المعزز فتطبيقات الواقع المعزز تقدم محتوى تعليمي مختلف من خلال تمثيلات كائنات ثلاثية الأبعاد نابضـة بالحياة مما يوفر للمتعلمين • انغماس أكبر وتعلم أعمق (Mayer, Moreno, 2003) 
ء) تيسر تعلم الأشكال الهندسية ودراسة الجغرافيا: فتطبيقات الواقع المعزز ييسر تعلم الأشكال

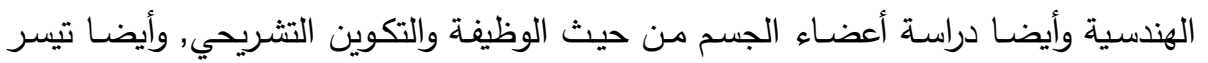
تقنية الواقع المعزز تعلم الجغرافيا, فلقد قام هيدلى (2003) Hedley بدراسة أثر استخدام

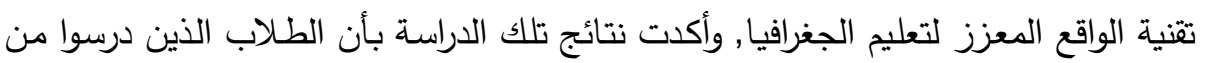

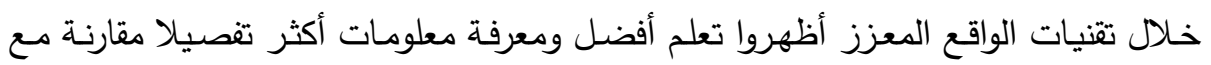

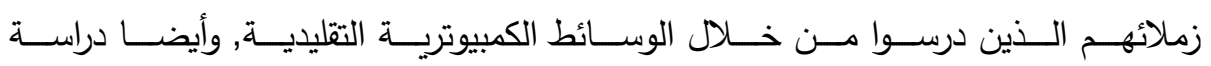

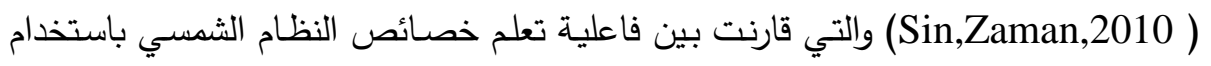

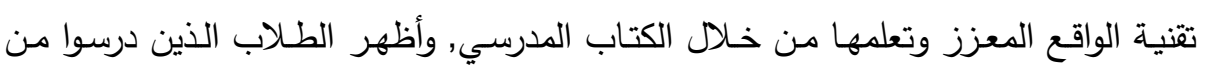

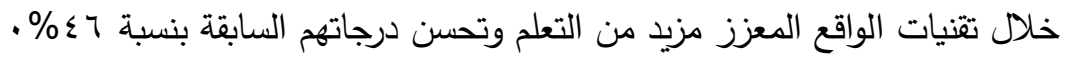

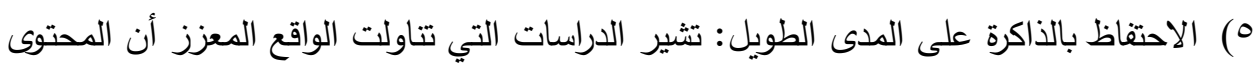

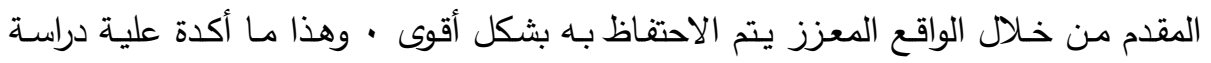

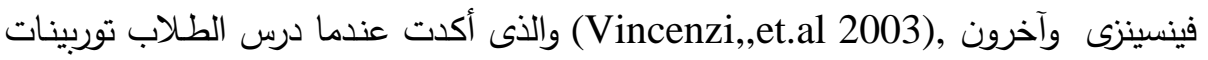
الطائرات فإن المحتوى التعليمي المستفاد كان أكثر بقاء مقارنة بالمحتوى المستفاد من خلال

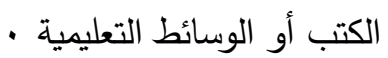
ج) تحسين أداء مهام الصيانة والمهام الجسدية: فتقنية الواقع المعزز أكثر فاعلية من استخدام

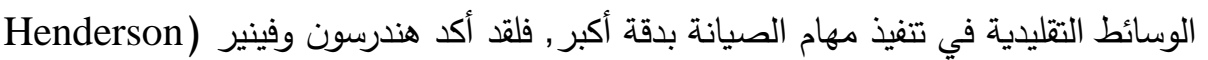
and Feiner(2011

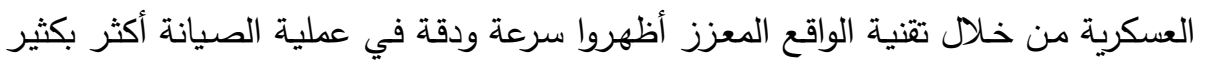
من الطلاب الذين درسوا بالطرق التقليدية . إجراءات البحث الطلاب الجن سار البحث الحالي وفقا لما يلى: • الاطـلاع على الأدبيات والمراجـع والكتب العربية والأجنبية والدراسـات والبحوث السـابقة ذات

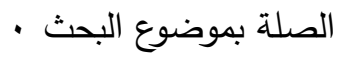
ه إعداد قائُة تقدير للنشاط الزائد لاختيار عينة البحث من أطفال الروضـة ذوى النشاط الزائد وتمثلت أهداف تلك القائمة في تحديد السمات الخاصة بالأطفال ذوى النشاط الزائد وتقسيمها في

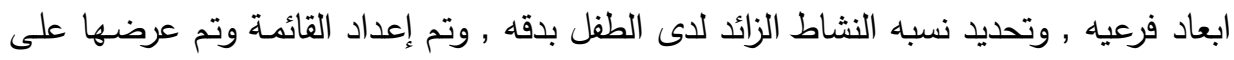
المتخصصين وإجراء التعديلات أصبحت قائمة تقدير النشاط الزائد فى صورتها النهائية تتكون 
من r أبعاد رئيسيه للنشاط الزائد لدى أطفال الروضة وتضمن المحور الأول (الحركة العشوائية

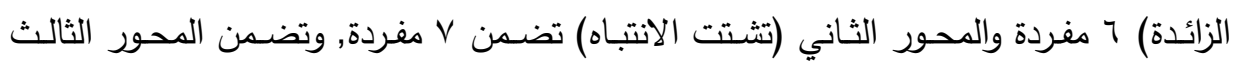

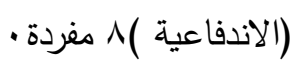

• إعداد قائمة مهارات تعلم المفردات اللغوية للأطفال الروضة ذوى النشاط الزائد , وقامت الباحثة بإعداد القائمة في صورتها الأولية وعرضها على على اساتذة مناهج وطرق تدريس اللغة الإنجليزية وذلك للحكم على قائمة مهارات تعلم مفردات اللغة الإنجليزية للأطفال ذوى النشاط الزائد , واتفق الإنق

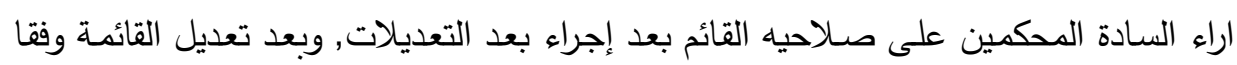

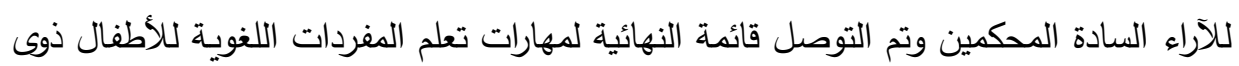
النشاط الزائد واشتملت على r مهارات أساسية و آمهارات فرعيه.

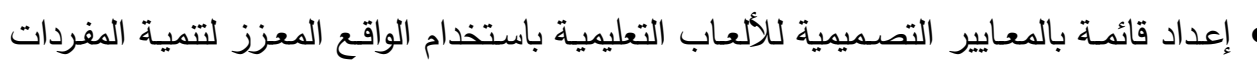

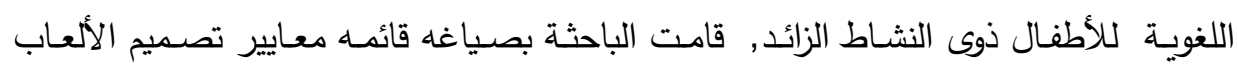

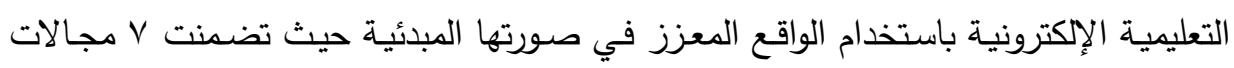
رئيسيه وهم الاهداف التعليمية للألعاب, والمحتوى التعليمي, والثكل, والاثارة والتعزيز ومستوى لإنى

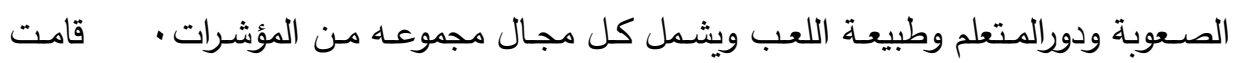

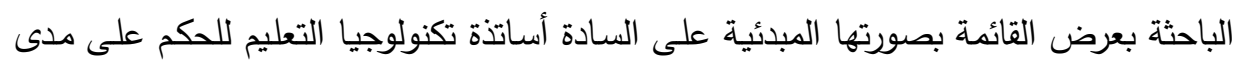
صلاحيه القائعة لتصميم الألعاب التعليمية باستخدام الواقع المعزز وللحكم على مدى ملى ملائمه

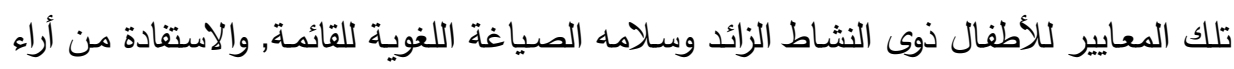

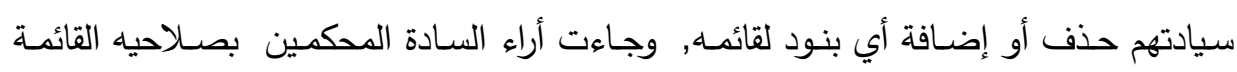

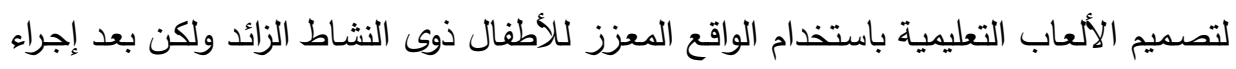

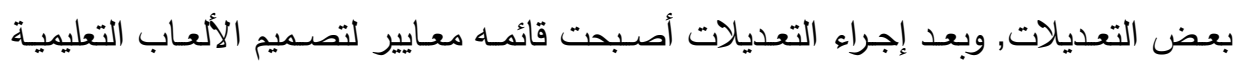

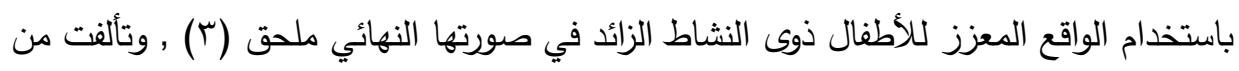

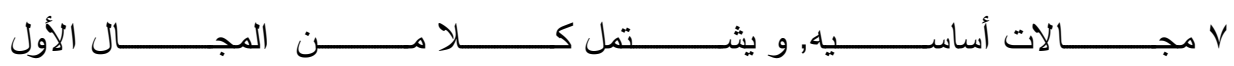
( الاهداف التعليميـة للألعـاب) والمجال الثاني (المحتوى التعليمي) والمجـال الرابع (التعزيـز

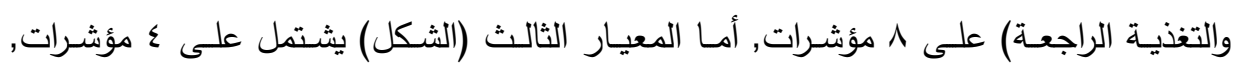

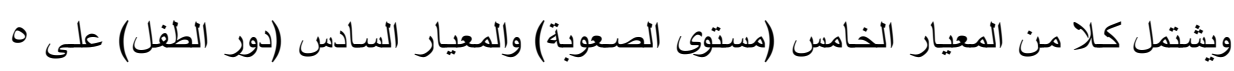
مؤشرات بينما يثتمل المعيار السابع (طبيعة اللعب ) على مؤشران • 
• إعداد اختبار مفردات لغويـه لقياس مدي فاعلية الألعاب الالكترونية باستخدام الواقع المعزز

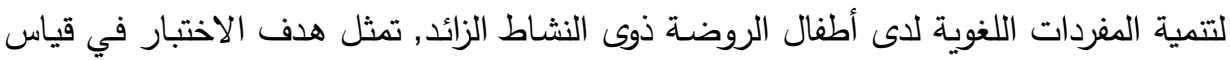

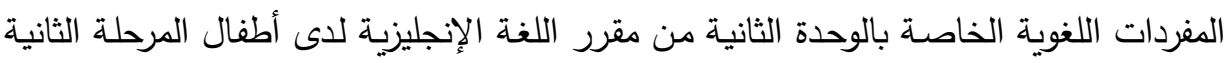

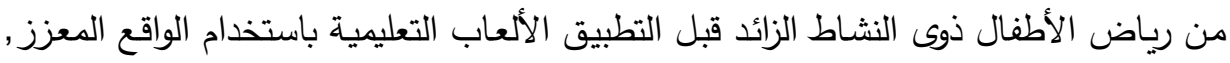

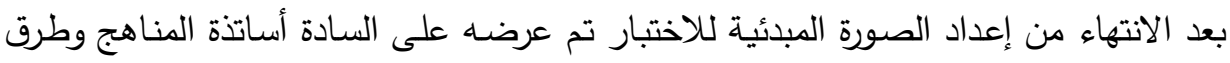

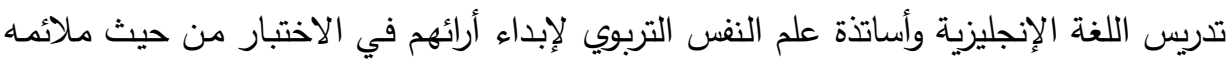

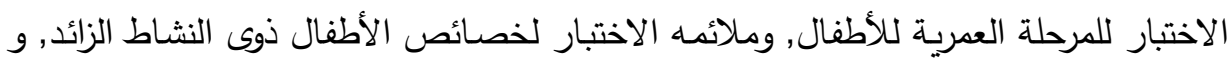
تتوع ووضوح الأسئلة والصور والرسوم , وبعد إجراء التعديلات المقترحة من السادة المحكمين

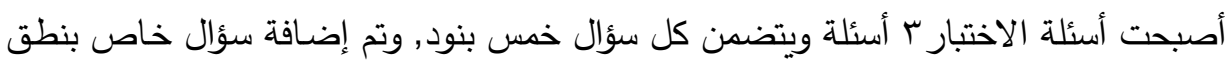

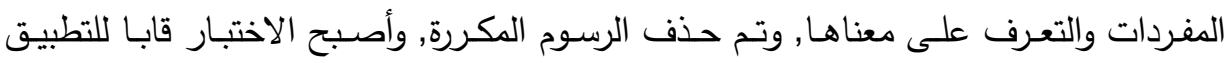
- استطلاعيا تصميم وتطوير اللعبة الاككترونية باستخدام الواقع المعزز بهدف استخدامها لتتميه المفردات

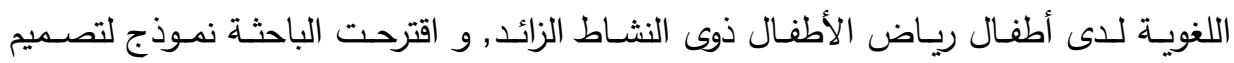
الألعاب التعليمية الإلكترونية باستخدام الواقع المعزز موضوع البحث الحئ الحالي وتضمن النموذج

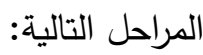
ا. . مرحلة التحليل وتتضمن تحديد خصائص المتعلمين وفئتهم العمرية, وتحديد المستوى التعليمي

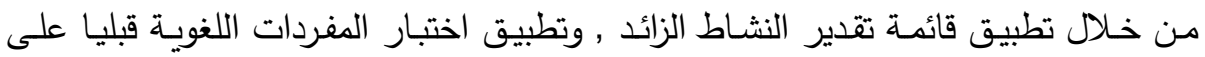

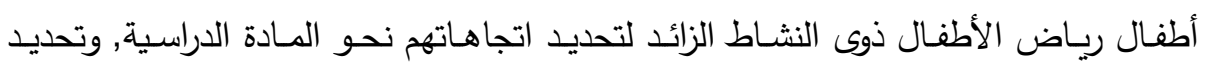

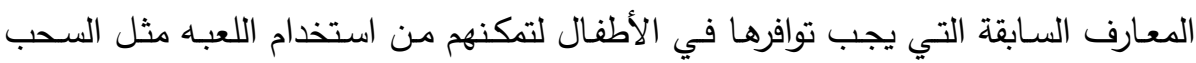

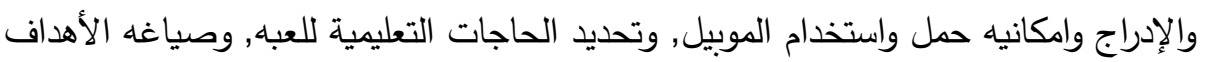

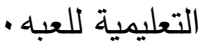
r. مرحلة التصميم: وتثمل تحديد عناصر المحتوى, وبناء الاختبارات المحكيه, وتصميم محتوى اللعبة r. مرحلـة الإنتاج: وتضمنت اختيار برنـامج تصميم اللعبـة , و تحديد عناصـر اللعب وتحديد التفاعلات بينها, وانتاج اللعبة • ع. مرحله التجريب المصغر للعبه على عينه مماثله لعينه الدراسة: حيث تم تطبيق اللعبة تجريبيا

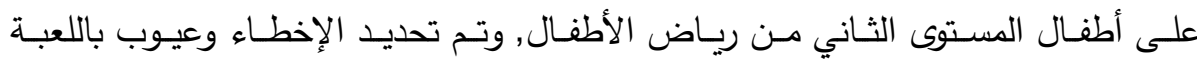


والمشكلات التي واجهت الأطفال أثناء استخدام اللعبة وتمثلت تلك المشكلات في ثقل وزن

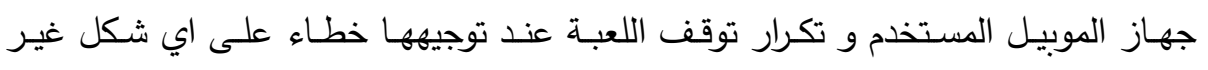
الكروت الخاصة باللعبة وقد تم إصلاح المشكلة .

๑. مرحله الاستخدام : تم تطبيق اللعبة التعليمية موضوع على عينه متكافئة من أطفال المرحلة

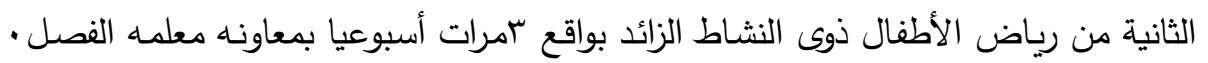

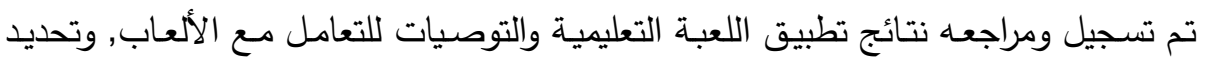

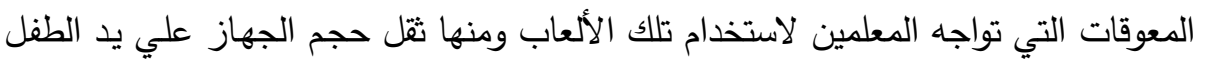
وقصر وقت الحصه وتفضيلهم للطرق التقليدية لتدريس المفردات اللغوية .

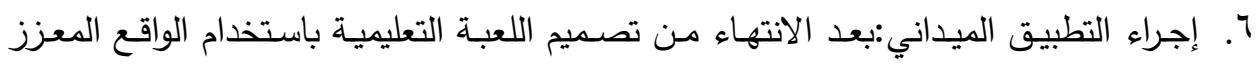

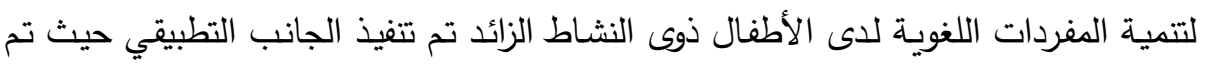
اختيار عينه البحث بصورة قصديه من خلال تطبيق قائمة تقدير النشاط الزائد على أطفال

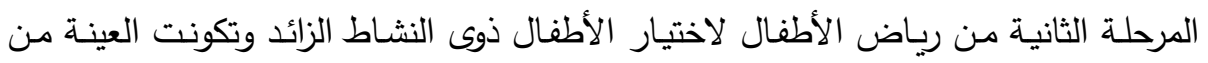
(Y (Y) طفل (9) بنين (ץ) بنات تم تقسيمهم بالتساوي على مجموعتين الضابطة والتجريبية

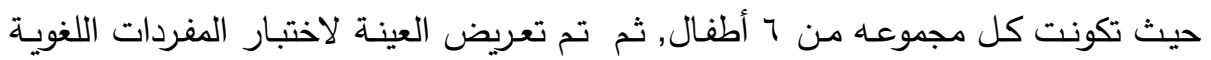
المعد مسبقا لتحديد أثر المتغيرالمستقل وهوالألعاب التعليمية المصممة باستخدام الواقع المعزز

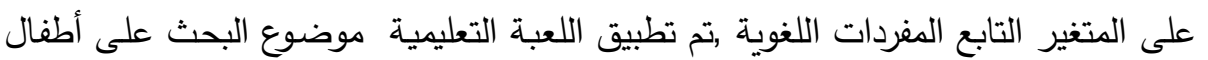

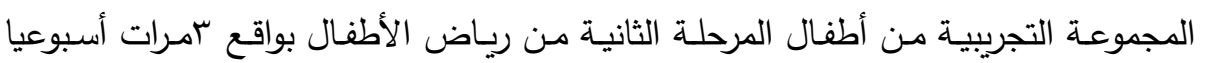

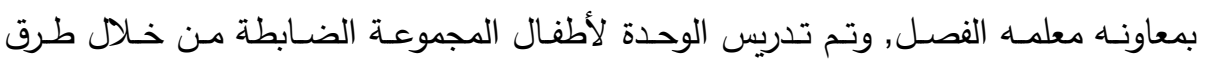
التدريس التقليدية بواقع سمرات, ثم قامت الباحثة بتطبيق الاختبار بعديا على المجموعتين

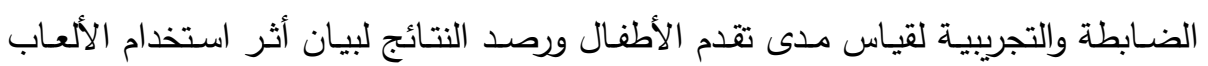

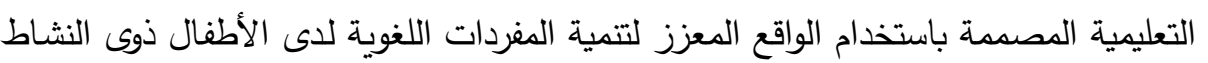

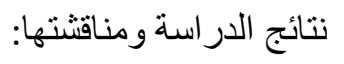

تمت الإجابة عن السؤال الأول: "مـا مهارات تعلـم المفردات اللغويـة لأطفـال ذوى النشـاط الزائد؟" بالفصل السابق, والتوصل لقائمة مهارات تعلم المفردات اللغويـة لأطفال ذوى النشاط الزائد,

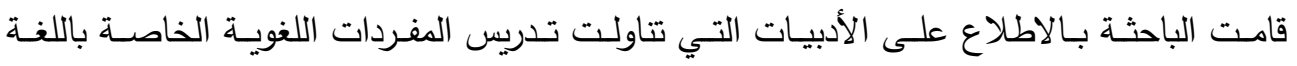

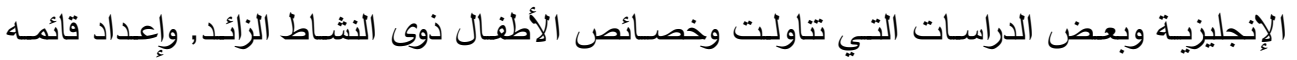


المهارات في صورتها الأولية, ثم عرض القائمسة على السادة المحكمين, وتعديلها وفقا لأرائهم, ثم عرض قائمه المهارات في صورتها النهائية . تمت الإجابة عن السؤال الثاني: "ما معايير تصميم ألعاب تعليمية باستخدام الواقع المعزن

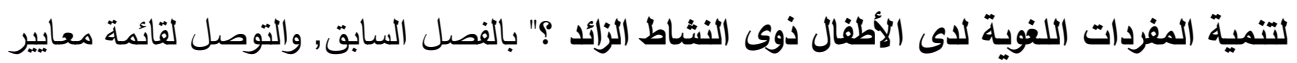

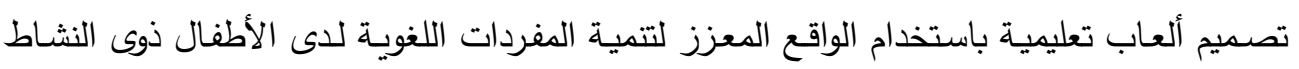

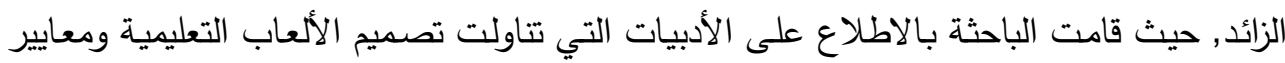

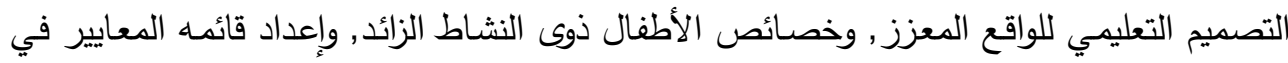

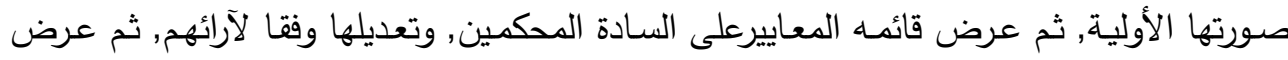
قائمه المعايير في صورتها النهائية.

للإجابة عن السؤال الثالث:" مـا التصـيم التعليمسي للألعـاب التعليميـة باسـتخدام الواقـع

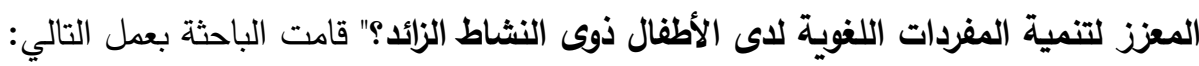

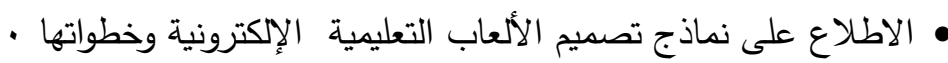

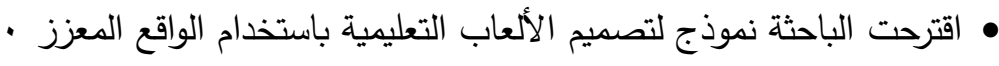
• تجهيز الرسوم, والنصوص, والمقاطع الصوتيه.

• تصميم السيناريو الخاص اللعبة التعليمية موضوع البحث في صورته ولهوله النهائية . • إنتاج اللعبة في صورتها المبدئية, وتم عرضها على المختصين وإجراء التعديلات .

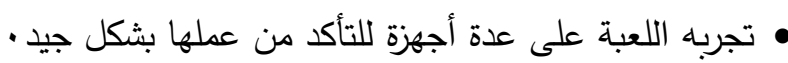

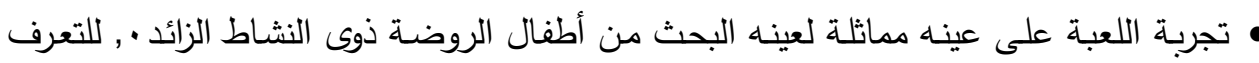

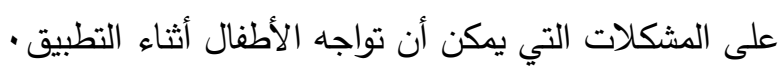
• تم حل المشكلات التي واجهت المتعمين وتم عرض اللعبة في صورتها النهائيه.

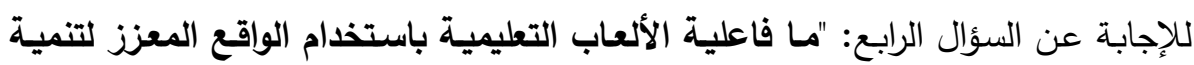

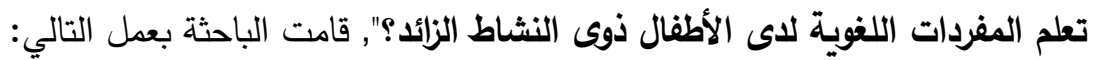
• تطبيق الاختبار القبلي على المجموعة الضابطة و المجموعة التجريبيه • • تطبيق اللعبة التعليمية بواقع ب مرات أسبوعيا على المجموعة التجريبيه .

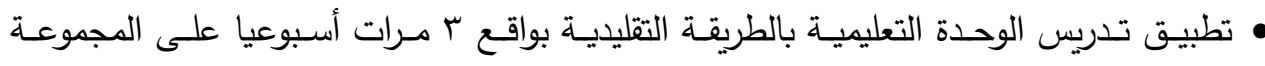
الضابطه. 
• تطبيق الاختبار التحصيلي بعديا على المجموعـة الضـابطة والمجموعـة التجريبيـة, ثم رصد

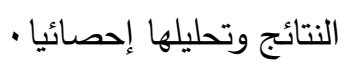

اختبر البحث صحة الفرض الأول والذى نص على " يوجد فرق دال إحصائيا عند مستوى إنى دلالة (ه ., •) بين متوسط رتب المجموعة الضابطة والمجموعة التجريبية في التطبيق البعدي

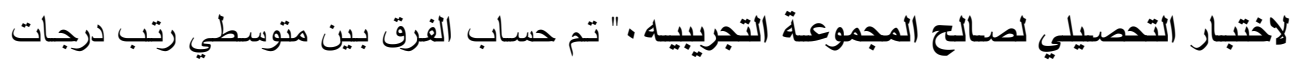

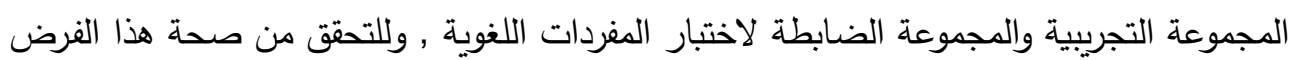
قامت الباحثة بحساب قيمة مان ويتتي(U) (للمقارنـة بين مجموعتين مستقلتين) لمستويات اختبار المفردات اللغويه والدرجة الكلية لمجموعتي البحث، ويمكن توضيح ذلك من خلال الجدول الآتي: قيمة (U) ودلالتها الإحصائية للفرق بين متوسطي رتب المجموعة التجريبية

\begin{tabular}{|c|c|c|c|c|c|c|c|}
\hline & & & طبيق البعدي & مابطة في & & & \\
\hline مستوى الدلالة & قيمة (Z) & قيمة (U) & مجموع الرتب & متوسط الرتب & ن ن & المجموعات & المستويات \\
\hline \multirow{3}{*}{ دالة ع. } & \multirow{3}{*}{2.9} & \multirow{3}{*}{$\cdot, \cdots$} & 57.00 & 9.50 & 1 & التجربية & \multirow{3}{*}{ الدلية } \\
\hline & & & 21.00 & 3.50 & 9 & الضانطة & \\
\hline & & & & & Ir & المجموع & \\
\hline
\end{tabular}

ويتضح من نتائج الجدول السابق وجود فرق ذات دلالمة إحصائية بين متوسط رتب درجات

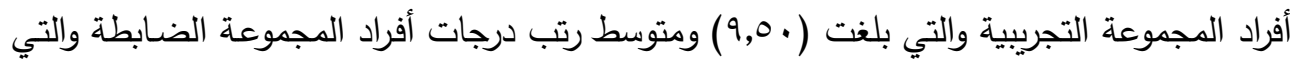
بلغت (·, بر) في التطبيق البعدي لاختبار المفردات اللغوية للأطفال ذوى النشاط الزائد, حيث بلغت

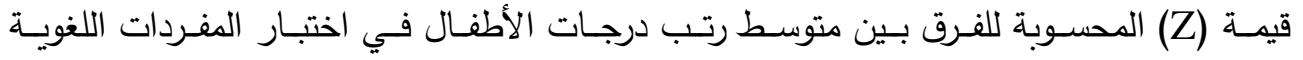

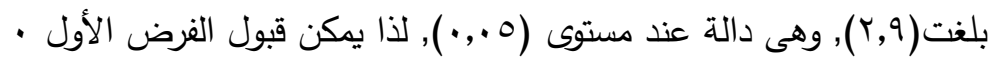

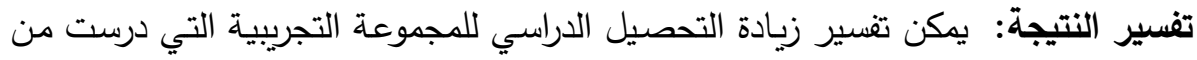

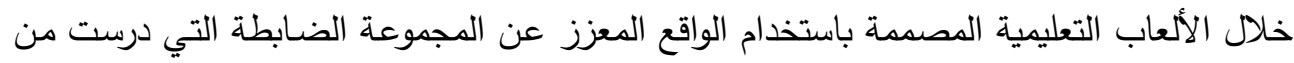

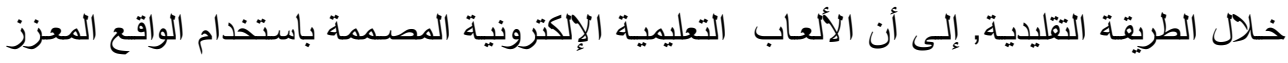

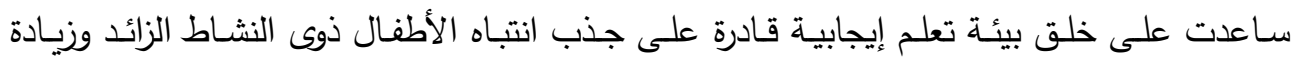
تركيزهم, ومن خـلال ما وفرته اللعبة التعليمية من تغذية راجعة فوريـة وجذابة للأطفال روما توفره

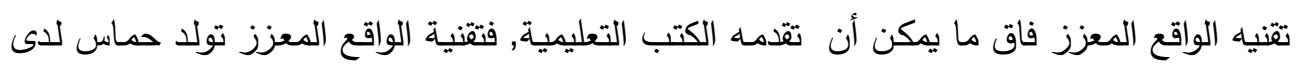

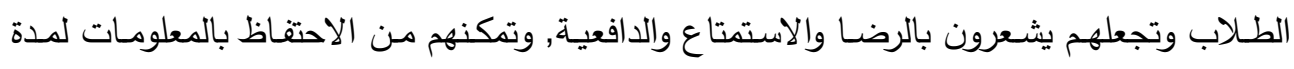


أطول نظرا لان المحتوى المقدم من خلال تقتيات الواقع المعزز هو أكثر جذرا في الذاكرة مقارنة بما يمكن أن يتعلمه الطالب من خلال الوسائل التقليدية .

اختبر البحث صحة الفرض الثاني والذى نص على" يوجد فرق دال إحصائيا عند مستوى لهن

دلالة (ه . , ·) بين متوسطي درجات المجموعة التجريبية في التطبيق القبلي والبعدي للاختبار

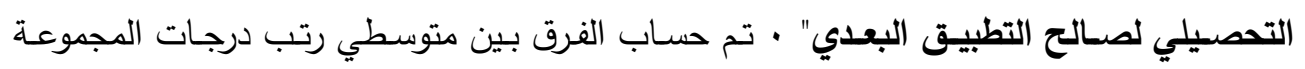

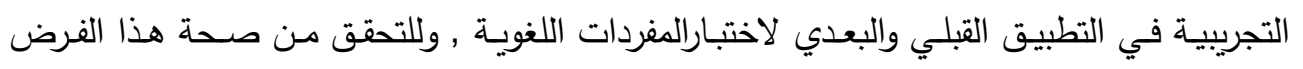

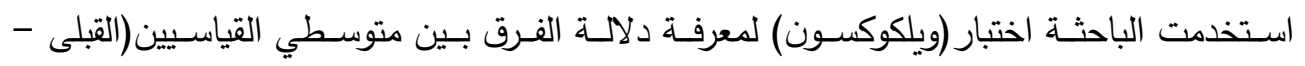

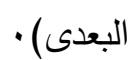
قيمة (Z) ودلالتها الإحصائية للفرق بين متوسط رتب المجموعة التجريبية في

\begin{tabular}{|c|c|c|c|c|c|c|}
\hline مستوى الالالة & قيمة (Z) & مجموع & متوسط الرتب & ن & الرتب & المستويات \\
\hline \multirow{4}{*}{ دالة عند ه., . } & \multirow{4}{*}{$r, r$} & $\cdot$ & . & . & السالبة & \multirow{4}{*}{ الدرجة الكلية } \\
\hline & & ri & $r, o$. & 7 & الموجبة & \\
\hline & & & & . & المتعادلة & \\
\hline & & & & 7 & المجموع & \\
\hline
\end{tabular}

يتضح من نتائج الجدول السابق وجود فرق ذات دلاله إحصائية بين متوسط درجات طلاب

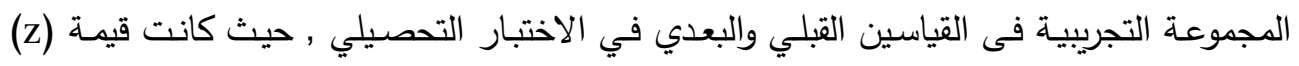

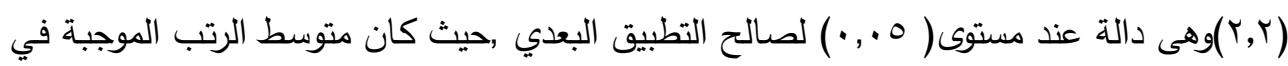

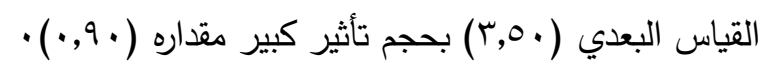

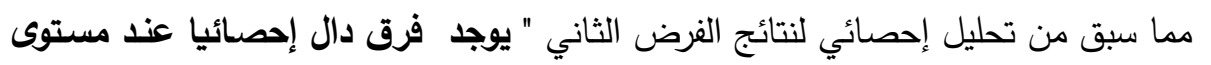
دلالـة (ه ., •) بين متوسطي درجات المجموعة التجريبية في التطبيق القبلي والبعدي للاختبار

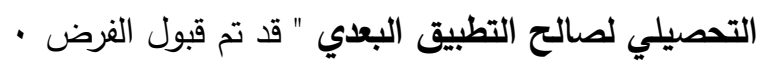
توصيات البحث: في ضوء النتائج التي توصل لها البحث يمكن تقديم التوصيات التالية: ا. ضـرورة توظيف الألعاب التعليمية باستخدام الواقع المعزز في تعليم منهج اللغـة الإنجليزيـة

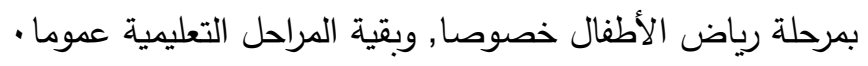

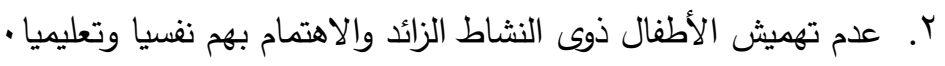


r. ت تطوير العملية التعليمية بما يتتاسب وخصـائص الاطفال ذوى النشاط الزائد, وتوفير عوامل

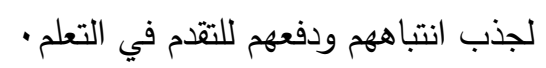

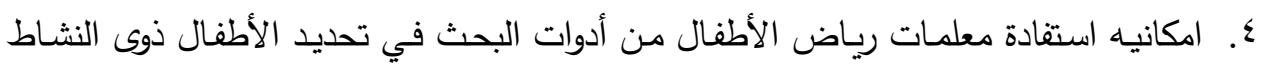

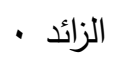

•. امكانيه استفادة معلمات رياض الأطفال من اللعبة التعليمية المصممة باستخدام الواقع المعزز

$$
\text { في تتمية المفردات اللغوية لدى أطفال الرياض ذوى النشاط الزائد . }
$$

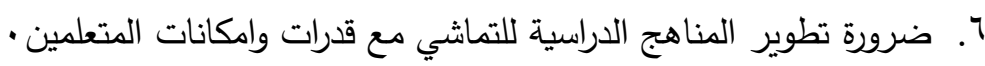

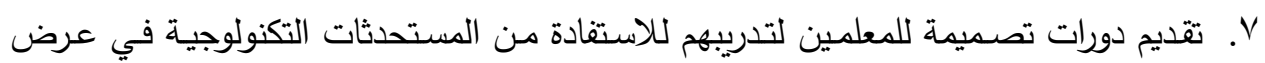
المواد التعليمية -

$$
\text { مقترحات البحث: }
$$

\section{في ضوء نتائج البحث يمكن تقديم المقترحات التالية:}

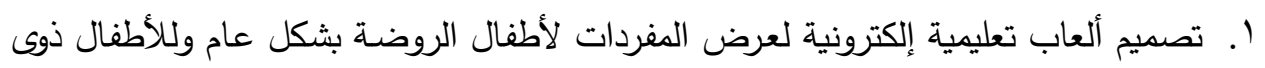

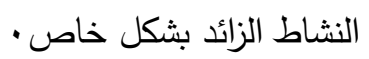

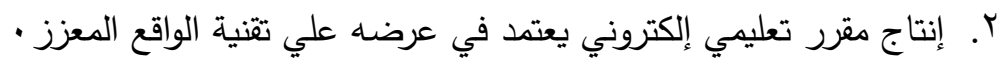

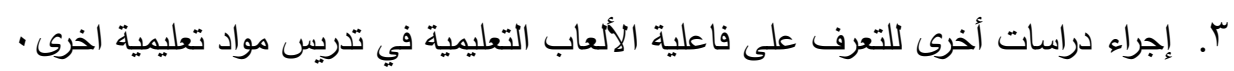

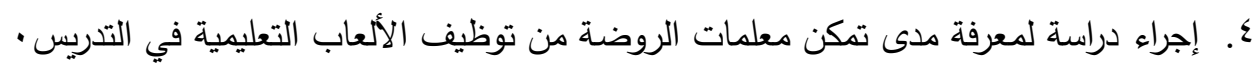

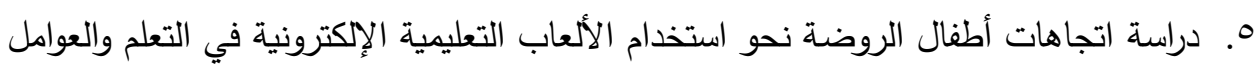

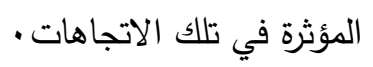

المر اجع:

أولا : المراجع العربيه

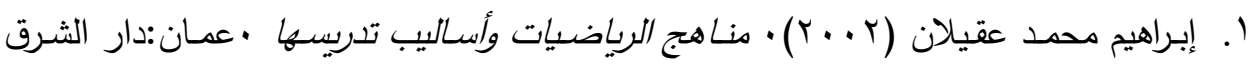

$$
\text { للطباعة . }
$$

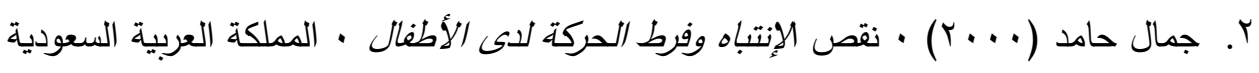

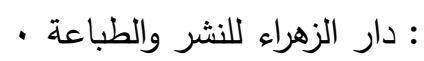

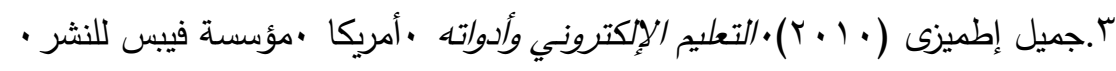

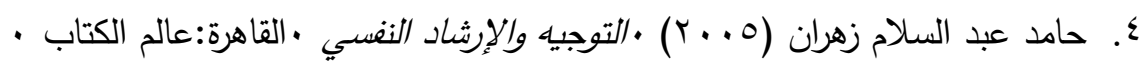

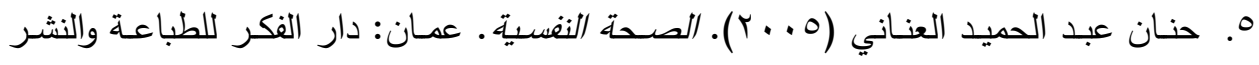

$$
\text { والتوزيع. }
$$




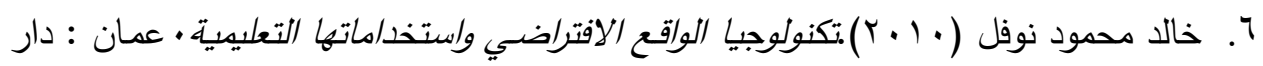

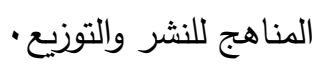

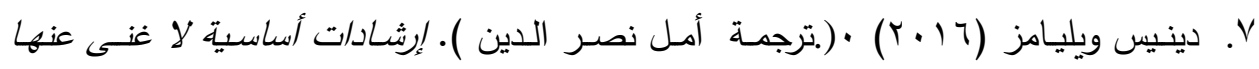

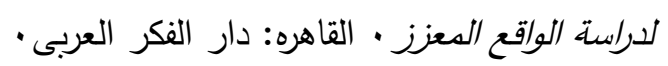

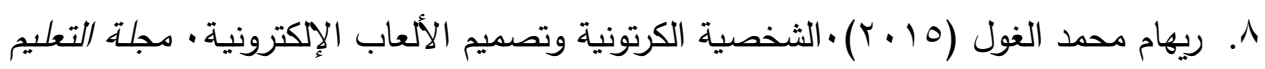

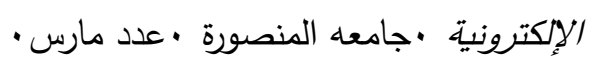

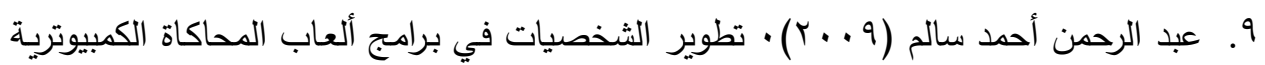

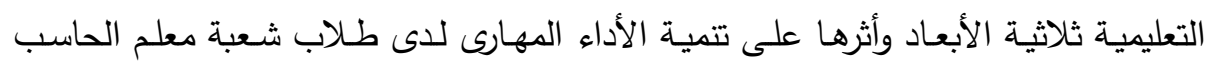

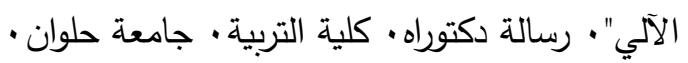

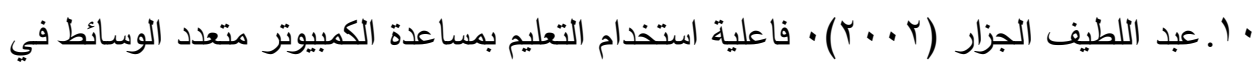
اكتساب بعض مستويات تعلم المفاهيم العلمية وفق نموذج "فراير" تقويم المفاهيم •مجلة كلية

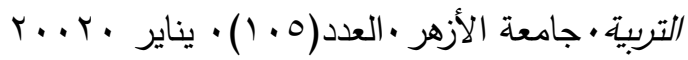

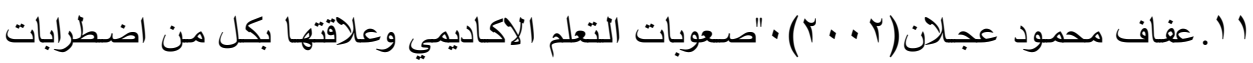
القصـور في الانتباه - النثـاط المفرط واضطراب السلوك لدى تلاميذ المرحة الابتدائية" .

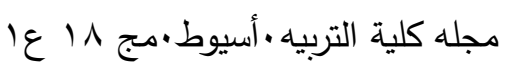

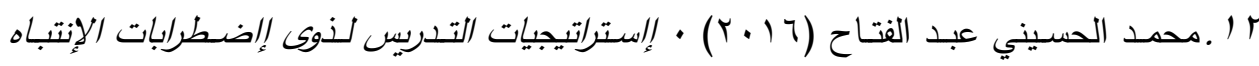

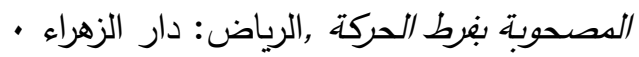

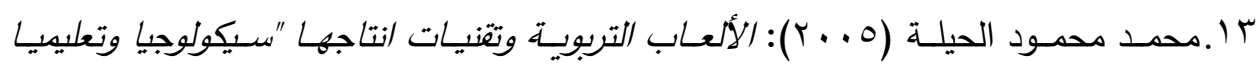

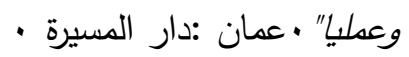

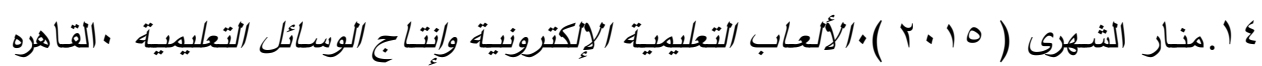
: مكتبة الأنجلو المصريه.

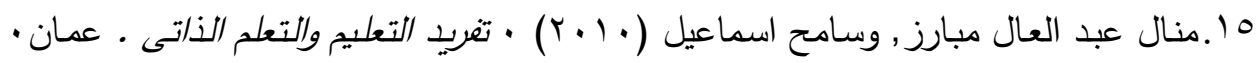
الإردن •دار الفكر

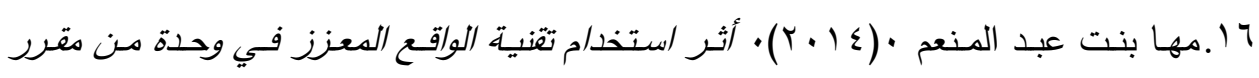

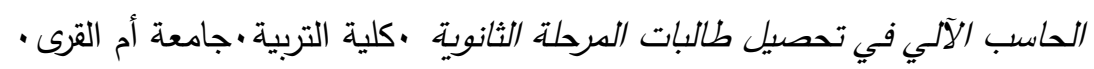

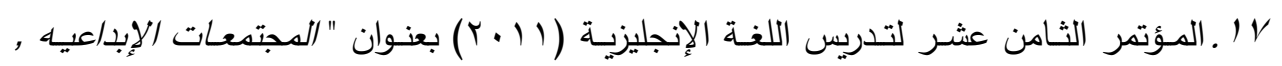

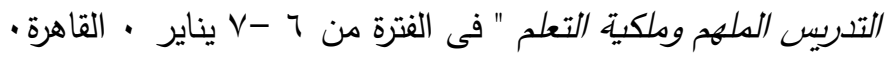


1 ا ـالمؤتمر العلمى الرابع عشر للجمعية المصرية لتكنولوجيا التعليم بالتعاون مـع كلية التربية

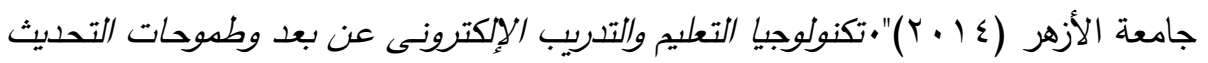

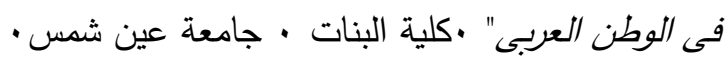

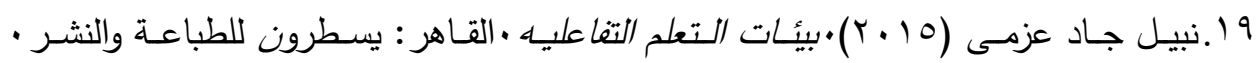

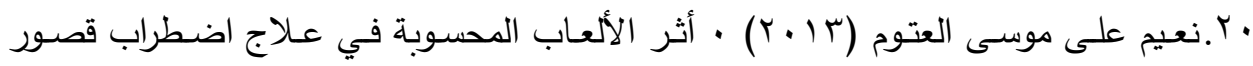

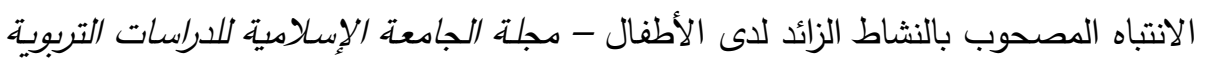
والنغسية -فلبسطين الأباه

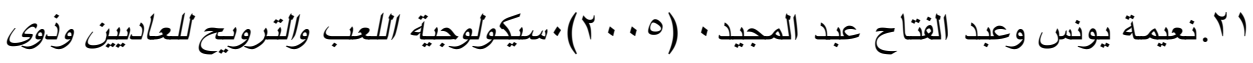

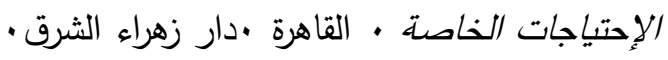

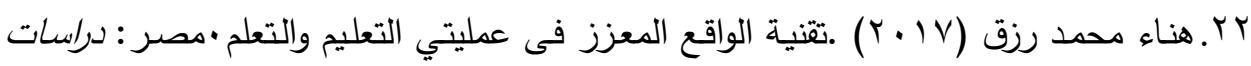

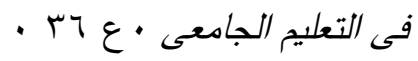

r r .وداد بنت عبد الله بـن عبد العزيز الثـترى • ريـم بنت عبد المحسن بـن محمد العبيكان

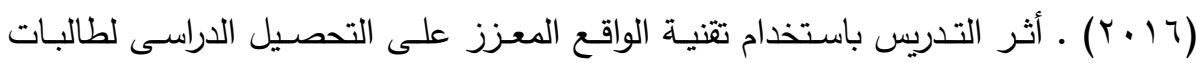

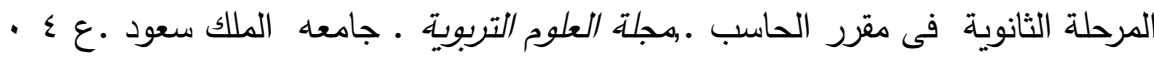
ثانيا : المر اجع الأجنبيه

24. Azuma,Baillot,et,al(2011). Recent advances in augmented reality. IEEE Computer Graphics and Applications,21(6),34-47.

25. Coshran M (2005).Cognitive behaviora psycholotherapy for anxiety and depressive disorders. Journal of the American acdemy of child and a doles psyghiatry,p.p. 12

26. Derryberry,A.(2007).Serious games: Online games for learning, Adobe Systems Incorporated: USA,(Available at: http://www.adobe.com/resources/elearning /pdfs/seriouse_games_wp.pdf),[1/1/2010]

27. Feil,J.\&Scattergood,M.(2005).Beginning Game Level Design, Thomson Ciurse Technology PTR:USA.

28. Frolova , Natalia(2017): Electronic Means of Foreign Language Learning in the System of Higher Education. Educational Research and Reviews, v12 n3 p116-119

29. Hedley NR (2003) Empirical evidence for advanced geographic visualization interface use. In: International cartographic congress, Durban. 
30. Henderson S, Feiner S (2011) Exploring the benefits of augmented reality documentation for maintenance and repair. IEEE Trans Visual Compute Graph 17:1355-1368.

http://dx.doi.org/10.1016/J.compedu

31. John Thompson(2007). "Is Education 1.0 Ready for Web 2.0 Students?," Innovate: Journal of Online Education: Vol. 3 : Iss. 4 , Article 5.

32. Kaidr,Iris (2004):Cognitive behaviora psycholo therapy for anxiety and depressive disorders in children and adolescents .Journal of the American academy of child and adoles psyghiatry,p.p.130-137.

33. Kipper \&Rampolla (2013). Augmented Reality Affectness in High school Students' Learning Outcomes in English .A Dissertation presnted in partial fufillment of the Requirements for the Degree Doctorate of education. Grand Canyon University .Knowels,Trudy(2010): The kids behind label :understand ADHD Education Design ,Essential readings for Quick Review,v76,n3, .

34. Looser ,J (2007).AR Magic lenses: Addressing the challenge of focus and context in augmented reality . A thesis submitted in partial fulfillment of the requirements for the Degree of Doctor of Philosophy .university of Canterbury.

35. Mayer RE, Moreno R (2003) Nine ways to reduce cognitive load in multimedia learning. Educ Psychology 38:43-52.

36. Nguyen(2008):Closing the top learning from assessment presentation made at the university of Maryland Eastern shore Assessment workshop .princess Anne MD.

37. Patkar, R., Singh, P., \& Birji, S. (2013). Maker Based Augmented Reality Using Android Os. Journal of advanced research in computer science and softwear engineering, Vol. 3, No. 5, pp. 46-69.

38. Prensky,M.(2001). Digital Game-based Learning, McGraw-Hill. New York. Prensky,M.(2007).Students as Designers and Creators of educational computer games, Who else? Available at: $\quad$ http://www.marcprensky.com/writing/pensky/students as

Game Creators.

39. Sin AK, Zaman HB (2010) Live solar system (LSS): evaluation of an augmented reality book-based educational tool. International symposium in information technology, Kuala Lumpur, Malaysia, pp. $1-6$.

40. Vincenzi DA, Valimont B, Macchiarella N, Opalenik C, Gangadharan SN, Majoros AE (2013) The effectiveness of cognitive elaboration 
using augmented reality as a training and learning paradigm. In: Annual meeting of the human factors and ergonomics society, Denver, CO, USA, pp 2054-2058.

41. Wikipedia.(2009).Game

Testing,(Available

At: http://www.Wikipedia.org/Wiki/Game_Testingt,[8/1/2009].

42. Yuen., Yaoyuneyong, \& Johnson, E. (2011). Augmented reality: An overview and five directions for AR in education. Journal of Educational Technology Development and Exchange, 4(1), 119-140. 